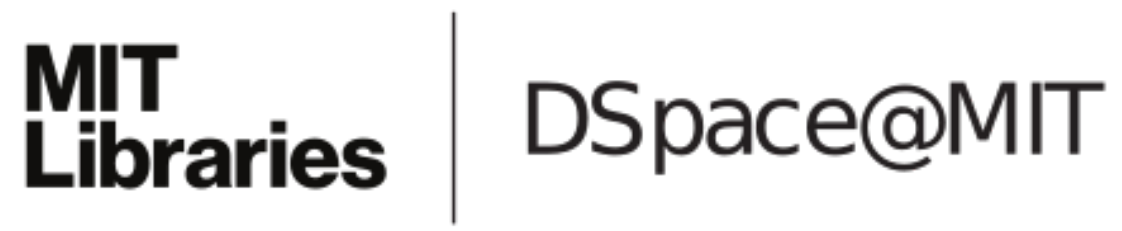

\author{
MIT Open Access Articles
}

Trade and Capital Flows: A Financial Frictions Perspective

The MIT Faculty has made this article openly available. Please share how this access benefits you. Your story matters.

Citation: Antràs, Pol, and Ricardo J. Caballero. "Trade and Capital Flows: A Financial Frictions Perspective." The Journal of Political Economy 117.4 (2009): 701-744.@ 2009 University of Chicago Press.

As Published: http://dx.doi.org/10.1086/605583

Publisher: University of Chicago Press

Persistent URL: http://hdl.handle.net/1721.1/61949

Version: Final published version: final published article, as it appeared in a journal, conference proceedings, or other formally published context

Terms of Use: Article is made available in accordance with the publisher's policy and may be subject to US copyright law. Please refer to the publisher's site for terms of use. 


\title{
Trade and Capital Flows: A Financial Frictions Perspective
}

\section{Pol Antràs}

Harvard University, National Bureau of Economic Research, and Centre for Economic Policy Research

\author{
Ricardo J. Caballero
}

Massachusetts Institute of Technology and National Bureau of Economic Research

\begin{abstract}
The classical Heckscher-Ohlin-Mundell paradigm states that trade and capital mobility are substitutes in the sense that trade integration reduces the incentives for capital to flow to capital-scarce countries. In this paper we show that in a world with heterogeneous financial development, a very different conclusion emerges. In particular, in less financially developed economies (South), trade and capital mobility are complements in the sense that trade integration increases the return to capital and thus the incentives for capital to flow to South. This interaction implies that deepening trade integration in South raises net capital inflows (or reduces net capital outflows). It also implies that, at the global level, protectionism may backfire if the goal is to rebalance capital flows.
\end{abstract}

We are grateful to Davin Chor, Arnaud Costinot, Elhanan Helpman, Kalina Manova, Jim Markusen, Roberto Rigobon, Rob Shimer, José Tessada, three anonymous referees, and seminar participants at Banco Central de Chile, Boston College, Brown, Connecticut, Gerzensee, Harvard, Hong Kong University, Michigan, Massachusetts Institute of Technology, London School of Economics, New York University, New York Fed, Oxford, Princeton, Stanford, University of California, Santa Cruz, Vanderbilt, Virginia, and the 2007 conference of the Nordic International Trade Seminars for useful comments. We thank Sergi Basco and especially Eduardo Morales for valuable research assistance and Davin Chor, C. Fritz Foley, and Kalina Manova for providing data. Caballero thanks the National Science Foundation for financial support.

[Journal of Political Economy, 2009, vol. 117, no. 4]

(C) 2009 by The University of Chicago. All rights reserved. 0022-3808/2009/11704-0004\$10.00 


\section{Introduction}

The process of globalization involves the integration of goods and financial markets of heterogeneous economies. While these two dimensions of integration are deeply intertwined in practice, the economics literature has kept them largely separate. International trade deals with the former and macroeconomics with the latter. In this paper we argue that such separation is not warranted when financial frictions are an important source of heterogeneity across countries and sectors. In particular, we show that in this context, trade and net capital flows are complements in less financially developed countries: a process of trade integration increases the incentives for capital to flow into these economies. In this context, a financially underdeveloped economy that opens the capital account without liberalizing trade is likely to experience capital outflows. An aggressive trade liberalization can reverse these outflows. At the global level, a rise in protectionism may exacerbate rather than reduce the so-called global imbalances.

While some of these implications may resonate with practitioners, they are in stark contrast with those that follow from the classical Heckscher-Ohlin-Mundell paradigm. In the neoclassical two-good, twofactor model, less developed economies are characterized as being capital scarce, and the model predicts that a process of trade integration reduces the incentives for capital to flow into these economies. Hence, trade and capital mobility are substitutes from the point of view of capitalscarce economies. Furthermore, in the absence of trade frictions, international specialization has the potential to bring about factor price equalization with the rest of the world, making international capital mobility altogether irrelevant. ${ }^{1}$

The key difference between our model and the Heckscher-OhlinMundell one, aside from the dynamic aspects that allow us to talk about savings and capital flows rather than just factor location, is the presence of financial frictions. Motivated by the findings of King and Levine (1993), Shleifer and Vishny (1997), Rajan and Zingales (1998), Manova (2008), and many others, we highlight two dimensions of heterogeneity in financial frictions. First, there is cross-country heterogeneity. The ability to pledge future output to potential financiers is higher in rich "North" than in developing "South." Second, there is cross-sectoral heterogeneity.

\footnotetext{
${ }^{1}$ The notion of substitutability in the Heckscher-Ohlin model has been interpreted in ways alternative to the one we emphasize here. For instance, it is sometimes associated with the prediction that international capital movements tend to reduce international trade flows. Other times, it is associated with the feature that trade and capital movements are alternative means to bring about factor price equalization across countries. As we shall see, in our model, capital movements may well increase trade flows across countries and factor price equalization attains only when both free trade and free capital mobility are allowed.
} 
Even when operating under a common financial system, producers in certain sectors find it more problematic to obtain financing than producers in others sectors. To paraphrase Rajan and Zingales (1998), some sectors are more "dependent" on financial infrastructure than others. In this context, both trade and capital flows become market mechanisms to circumvent the misallocation of capital induced by financial frictions in South. If we close the trade channel, then both physical and financial capital outflows from South become the vehicle through which the return to savers and the sectoral allocation of capital are improved in South. In contrast, with free trade, it is the reorganization of domestic production in South that does the heavy lifting and by doing so raises the return on capital in South and palliates or even reverses capital outflows.

In order to formalize these insights, in Section II, we develop a standard $2 \times 2$ (two-factor, two-sector) general equilibrium model of international trade in which firms hire capital and labor to produce two homogeneous goods. To capture the role of heterogeneous financial frictions across countries and sectors in the simplest possible way, we enrich the standard model by incorporating a financial market imperfection in one of the sectors while initially making the two sectors symmetric in every other respect. The financial friction limits the amount of capital allocated to the sector affected by it.

We first consider the autarkic equilibrium of this simple economy in which goods and factor markets have to clear domestically. In such a case, countries with worse financial institutions feature a lower relative price of the unconstrained sector's output (since a disproportionate share of resources ends up being allocated to this sector) and also feature relatively depressed wages and rental rates of capital. If we now allow capital to move across countries that differ only in financial development, capital flows from the financially underdeveloped South to the financially developed North.

These closed (to trade) economy outcomes are in sharp contrast to those when South can freely trade with a financially developed North. We show that in that case, South (incompletely) specializes in the unconstrained sector and thus becomes a net importer of the output of the "financially dependent" sector. From the point of view of South, trade integration raises the relative price of the unconstrained sector's output and the real rental rate of capital. Trade does not bring about factor price equalization, and the rental rate of capital ends up being higher in South than in North. This implied reversal in the direction of capital flows follows from the fact that in the free-trade equilibrium, wages in South remain depressed relative to those in North, which when combined with goods price equalization (a condition absent in the 
closed economy) ensures that capitalists earn a higher real return in South than in North.

Although we initially derive our conclusions for the case in which South is a small open economy and preferences and technologies are Cobb-Douglas, we later demonstrate that the complementarity between trade and capital mobility remains valid for general homothetic preferences and symmetric neoclassical production technologies. In particular, in a world in which countries differ only in financial development and sectors differ only in financial dependence, trade integration reduces the gap between the rental rate of capital in North and South, and with free trade, the rental rate of capital is higher in the less financially developed South.

Our benchmark model isolates the effects of cross-country and crosssectoral heterogeneity in financial frictions on the structure of trade and capital flows. In Section IV, we develop a more general model that introduces Heckscher-Ohlin determinants of international trade into our static model. In this general model, it continues to be the case that, regardless of factor intensity differences across sectors, trade integration raises the rental rate of capital in South as long as South has comparative advantage in the unconstrained sector. We further show that South will necessarily have comparative advantage in the unconstrained sector as long as differences in financial development across countries are sufficiently large. In the presence of large differences in aggregate capitallabor ratios across countries, certain asymmetries in production technologies across sectors could, however, translate into South gaining comparative advantage in the constrained sector. For instance, if the unconstrained sector happened to be much more capital intensive than the constrained sector, then the autarky relative price of the unconstrained sector might well be lower in the capital-abundant North than in South. Nevertheless, we find no empirical evidence suggesting that such troublesome cross-sectoral asymmetries in technology are relevant in the real world.

All the statements up to now follow from a static model in which the only possible type of capital flows involves reallocation of a given stock of physical capital across countries. In Section $\mathrm{V}$ we develop a dynamic model that illustrates that our mechanism has similar implications for capital flows driven by the allocation of savings across economies. Under the plausible assumption that neither labor income nor entrepreneurial rents are capitalizable, our model implies that countries with underdeveloped financial markets feature a relatively low return to savers under trade and financial autarky but a relatively high return to savers with free trade and financial autarky. It follows that, again, trade and capital inflows are complements in South.

Our paper relates to several literatures in international finance and 
international trade. From the point of view of international finance, the closest models are those studying the role of financial frictions in shaping capital flows. These models are typically cast in terms of one-sector models, where capital flows are the only mechanism to increase the return to capital in financially underdeveloped countries. The literature highlighting this mechanism is large and includes Gertler and Rogoff (1990), Boyd and Smith (1997), Shleifer and Wolfenzon (2002), Reinhart and Rogoff (2004), Kraay et al. (2005), and Caballero, Farhi, and Gourinchas (2008), as well as the recent (working) papers by Aoki, Benigno, and Kiyotaki (2006) and Mendoza, Quadrini, and Rios-Rull (2007). There is also a trade literature emphasizing the role of the interaction between financial development and financial dependence in shaping international trade flows. It includes the work of Bardhan and Kletzer (1987), Beck (2002), Matsuyama (2005), Wynne (2005), Ju and Wei (2006), Becker and Greenberg (2007), and Manova (2008). These papers, however, focus on deriving (and testing) implications for trade flows and do not allow for capital mobility. ${ }^{2}$ In terms of complementarities between trade and capital flows, our paper is related to Markusen (1983), though his notion of complementarity is quite distinct from ours. In particular, Markusen shows that capital mobility can increase gross trade flows in a variety of models in which comparative advantage is not driven by differences in capital-labor ratios across countries. In our paper, we focus on a different type of complementarity, one that runs from trade integration to net capital flows. Another difference between Markusen's paper and ours is that he did not explore the role of financial frictions, which are of course central in our context. ${ }^{3}$ Finally, in terms of comparative statics, our extended model with Heckscher-Ohlin elements has some similarities with the specific-factors model of Jones (1971) and Samuelson (1971). Although capital is not sector specific in our model, its allocation across sectors is pinned down by the parameters governing the tightness of the financial constraint. Amano (1977), Brecher and Findlay (1983), Jones (1989), and Neary (1995) study capital mobility within variants of the specific-factors model, but the conclusions generally depend on the assumed pattern of specialization and factor mobility.

\footnotetext{
${ }^{2}$ To be precise, sec. 2 of Matsuyama (2005) includes a discussion of capital flows, but the analysis in that section is developed in terms of a one-sector model and is thus more related to the international finance papers mentioned above.

${ }^{3}$ Martin and Rey (2006) study the effects of trade integration (modeled as an increase in market size) on the likelihood of a financial crash in an emerging economy. Their model emphasizes a risk-sharing rationale for capital flows, which is absent in our framework.
} 


\section{A Stylized Model of Trade with Financial Frictions}

In this section we develop our benchmark model. In order to isolate the main mechanism in the paper, we make a series of simplifying assumptions that we later relax in Sections IV and V. In particular, our benchmark model is static, imposes a specific log-linear structure, and abstracts from standard Heckscher-Ohlin determinants of comparative advantage.

\section{A. The Environment}

Consider an economy that employs two factors (capital $K$ and labor $L$ ) to produce two homogeneous goods ( 1 and 2$)$. The country is inhabited by a continuum of measure $\mu$ of entrepreneurial capitalists (or simply entrepreneurs), a continuum of measure $1-\mu$ of rentier capitalists (or simply rentiers), and a continuum of measure $L$ of workers. All capitalists are endowed with $K$ units of capital, and each worker supplies inelastically one unit of labor; so the aggregate capital-labor ratio of the economy is $K / L$, with a fraction $\mu$ of $K$ being in the hands of entrepreneurs and the remaining fraction being held by rentiers. We denote the rental rate of capital by $\delta$ and the wage rate by $w$.

All agents have identical Cobb-Douglas preferences and devote a fraction $\eta$ of their spending to sector 1's output, which we take as the numeraire:

$$
U=\left(\frac{C_{1}}{\eta}\right)^{\eta}\left(\frac{C_{2}}{1-\eta}\right)^{1-\eta} .
$$

Production in both sectors combines capital and labor according to

$$
Y_{i}=Z\left(K_{i}\right)^{\alpha}\left(L_{i}\right)^{1-\alpha}, \quad i=1,2,
$$

where $K_{i}$ and $L_{i}$ are the amounts of capital and labor employed in sector $i$, and $Z$ is a Hicks-neutral productivity parameter. From a technological point of view, entrepreneurial and rentier capital are perfect substitutes. Notice also that, for the time being, we focus on symmetric technologies to eliminate any source of comparative advantage other than financial development.

Goods and labor markets are perfectly competitive, and factors of production are freely mobile across sectors. If the capital market is also perfectly competitive, then the autarky equilibrium of this economy is straightforward to characterize. In particular, given identical technologies in both sectors, the marginal rate of transformation is equal to negative one, and thus the relative price of sector 2's output, $p$, is equal to one. It is then easily verified that the economy allocates a fraction $\eta$ of $K$ and $L$ to sector 1 and the remaining fraction $1-\eta$ to sector 2. If 
this frictionless economy is open to international trade and faces an exogenously given relative price $p$, then it completely specializes in sector 1 if $p<1$ and completely specializes in sector 2 if $p>1$.

\section{B. Financial Friction}

We shall assume, however, that the capital market has a friction. Consistently with the empirical literature discussed in the introduction, we assume that the financial friction has an asymmetric effect in the two sectors. To simplify matters, we assume that financial contracting in sector 2 is perfect in the sense that producers in that sector can hire any desired amount of capital at the equilibrium rental rate $\delta$.

Conversely, there is a financial friction in sector 1 , which we associate with the production process in that sector as being relatively "complex." We appeal to this complexity to justify the following two assumptions: (i) only entrepreneurs know how to produce in sector 1 (i.e., their "human capital" is essential in that sector); and (ii) because of informational frictions, producers in that sector (i.e., entrepreneurs) can borrow only a limited amount of capital. We capture the latter capital market friction in a stark (though standard in the literature) way by assuming that lenders are willing to lend to entrepreneurs only a multiple $\theta-1$ of the entrepreneur's capital endowment, so entrepreneur $i$ 's investment is constrained by

$$
I^{i} \leq \theta K^{i}=\theta K \text { for } \theta>1 .
$$

For the purposes of this paper we need not take a particular stance on what the friction is behind this borrowing constraint. It could be related to an ex post moral hazard problem, to limited commitment, or to adverse selection. In Appendix A, we develop a simple microfoundation for the financial constraint in a model with limited commitment on the part of entrepreneurs. ${ }^{4}$

Regardless of the source of the constraint, it is clear that if $\theta$ is sufficiently large, then entrepreneurs are able to jointly allocate a fraction $\eta$ of capital to the constrained sector 1 . In such a case, constraint (3) does not bind and the equilibrium is identical to that of the frictionless economy described above. Hereafter we focus on the more interesting case in which $\theta$ is low enough so that (3) binds. This requires the following assumption.

${ }^{4} \mathrm{~A}$ simplifying assumption in our setup is that the credit multiplier $\theta$ is independent of the rental rate $\delta$. Aghion, Banerjee, and Piketty (1999) provide a microfoundation for this rental rate insensitivity in a model with ex post moral hazard and costly state verification. Our model in App. A can also deliver such insensitivity, but we show that our main results are preserved in an alternative formulation in which $\theta$ is a function of factor prices. See Tirole (2006) for an overview of different models of financial contracting. 
Assumption 1. $\mu \theta<\eta$.

\section{Closed Economy Equilibrium}

We next turn to explore the autarky equilibrium of this economy with a particular emphasis on the determination of the rental rate of capital $\delta$. As noted above, under assumption 1 the financial constraint (3) binds, each entrepreneur invests an amount $\theta K$ (of which $[\theta-1] K$ is borrowed), and the aggregate amount of capital allocated to sector 1 is

$$
K_{1}=\mu \theta K<\eta K .
$$

This imposes that entrepreneurs invest all their endowment of $K$ in sector 1 and never become rentiers, but this is necessarily a feature of the equilibrium since, as we will see shortly, entrepreneurs can always obtain a higher return by doing so.

Because labor can freely move across sectors, it is allocated to equate the value of its marginal product, which using (4) implies

$$
(1-\alpha) Z\left(\frac{\mu \theta K}{L_{1}}\right)^{\alpha}=p(1-\alpha) Z\left[\frac{(1-\mu \theta) K}{L-L_{1}}\right]^{\alpha},
$$

where, remember, $p$ denotes the price of good 2 in terms of good 1 (the numeraire).

From the consumer's first-order condition and goods market clearing, we have

$$
(1-\eta) Z(\mu \theta K)^{\alpha}\left(L_{1}\right)^{1-\alpha}=p \eta Z[(1-\mu \theta) K]^{\alpha}\left(L-L_{1}\right)^{1-\alpha},
$$

which together with the labor market condition in (5) implies that

$$
L_{1}=\eta L
$$

and

$$
p=\left[\frac{\mu \theta(1-\eta)}{\eta(1-\mu \theta)}\right]^{\alpha}<1,
$$

where the inequality follows again from assumption 1 .

As indicated by equations (4) and (7), in our benchmark model, financial frictions do not distort the allocation of labor across sectors but shift capital to the unconstrained sector (sector 2). As a result, sector 2's output is "oversupplied" and its relative price $p$ is depressed. The tighter the financial constraint (the lower $\theta$ ), the lower the relative price $p$.

Financial frictions also have significant effects on the rental rate of capital $\delta$. To see this, notice that because only rentiers place their capital 
in sector 2, the rental rate of capital (in terms of the sector 2 output) will necessarily equal the marginal product of capital in that sector, that is,

$$
\frac{\delta}{p}=\alpha Z\left(\frac{1-\mu \theta}{1-\eta} \frac{K}{L}\right)^{\alpha-1}
$$

Using equation (8), we then also have that

$$
\delta=\frac{\mu \theta(1-\eta)}{(1-\mu \theta) \eta} \alpha Z\left(\frac{\mu \theta}{\eta} \frac{K}{L}\right)^{\alpha-1} .
$$

Note that both $\delta / p$ and $\delta$ are increasing functions of the degree of financial contractibility $\theta$. Other things equal, less financially developed economies feature depressed rental returns to capital. The intuition for this result is clear: a tighter borrowing constraint reduces the ability of the constrained sector to attract capital, thus increasing the capital-labor ratio in the unconstrained sector and reducing its marginal product in terms of sector 2 output (i.e., reducing $\delta / p$ ) and also in terms of the numeraire good (remember that $p$ also falls in $\theta$ ).

So far we have been silent on the return obtained by entrepreneurs. In the frictionless economy, entrepreneurial and rentier capital are perfect substitutes and both obtain a common rental rate $\delta$. However, when the borrowing constraint (3) binds, entrepreneurial capital becomes relatively scarce and entrepreneurs obtain a premium over the equilibrium rental rate of capital. In particular, their return per unit of capital is

$$
R=\delta+\lambda \theta,
$$

where $\lambda$ is the Lagrange multiplier corresponding to the financial constraint (3). ${ }^{5}$ In equilibrium, the marginal product of capital in the constrained sector 1 needs to equal $\delta+\lambda$, from which we obtain

$$
\lambda=\left[1-\frac{\mu \theta(1-\eta)}{(1-\mu \theta) \eta}\right] \alpha Z\left(\frac{\mu \theta}{\eta} \frac{K}{L}\right)^{\alpha-1}
$$

which is strictly positive (under assumption 1) and also decreasing in $\theta$. Hence, the shadow value of entrepreneurial capital is higher in economies with less developed financial markets. In sum, we have shown the following proposition.

\footnotetext{
${ }^{5}$ The return $R$ follows from $R=\theta(\delta+\lambda)-(\theta-1) \delta$. Notice that the fact that $R>\delta$ justifies our assumption above that entrepreneurs invest all their endowment of capital in sector 1 . Furthermore, given that we have constant returns to scale in all factors, the Lagrange multiplier $\lambda$ would be common to all entrepreneurs even if their endowments of $K$ were not identical. This feature will become useful in the dynamic version of the model.
} 
Proposition 1. In the closed economy equilibrium, an increase in financial contractibility $\theta$ raises the relative price of the unconstrained sector and the real rental rate of capital and reduces the shadow value of entrepreneurial capital.

It is worth noting that the last statement in the proposition does not imply that the welfare of entrepreneurs is necessarily decreasing in $\theta$. In particular, it is easily verified that entrepreneurs would always favor an increase in $\theta$ whenever the initial $\theta$ is low and $\alpha$ is large enough. Finally, it also straightforward to show that both real wages (measured in terms of the ideal price index associated with [1]) and welfare are increasing in $\theta$. In sum, economies with more developed financial systems necessarily attain higher real wages and welfare levels.

\section{Open Economy Equilibrium}

Consider now a world economy consisting of two countries (North and South) of the type described above. In order to isolate the role of financial development in shaping trade and capital flows, we assume that the two countries are identical in all respects except for their level of financial development and their size. In particular, both countries share common preferences and technologies-as in (1) and (2)-and are endowed with the same capital-labor ratio, but North is more financially developed $\left(\theta^{N}>\theta^{S}\right)$ and is also much larger (though we show in the next section that our substantive implications do not depend on this assumption). In the absence of trade in goods between these two countries, the equilibrium in each economy is as described above, and we can conclude from proposition 1 that the relative price $p$ and the real rental rate of capital $(\delta, \delta / p)$ are lower in South than in North.

We next compare this situation to one in which North and South can freely trade goods between themselves. Because we are particularly interested in the effects of trade liberalization in South, we focus for now on the case in which North is so large relative to South that the freetrade equilibrium relative price $p$ corresponds to the autarky one in North, that is,

$$
p=p_{\text {aut }}^{N}=\left[\frac{\mu \theta^{N}(1-\eta)}{\eta\left(1-\mu \theta^{N}\right)}\right]^{\alpha}<1 .
$$

In other words, South is now a small open economy facing a fixed world relative price $p>p_{\text {aut }}^{s}$ (see proposition 1 ). The inequality in (12) reflects our assumption that financial constraints bind in North as well. In Section IV, we study the more general case of trade integration between two sizable economies and also briefly consider the possibility that financial constraints do not bind in North (see n. 22). 


\section{Trade Integration and the Rental Rate of Capital}

Let us then study the equilibrium of a small open economy with a level of financial development given by $\theta \cdot{ }^{6}$ As argued at the end of Section II.A, whenever facing a relative price $p<1$, a frictionless small South would like to fully specialize in the production of good 1 . However, the borrowing constraint in that sector prevents this by limiting the aggregate allocation of capital to that sector to be no larger than $\mu \theta K$. Thus, as long as $p<1$, Southern entrepreneurs continue to obtain a premium when allocating their capital to sector 1 , and as a result, the distribution of capital across sectors is identical to that in the closed economy.

Conversely, the allocation of labor across sectors is affected by the access to international trade in goods. Condition (5) equating the value of the marginal product of labor across sectors still needs to hold in equilibrium, but the allocation of labor no longer needs to be consistent with goods market clearing as dictated by equation (6) above. This is the distinguishing effect of international trade in the model: it detaches the allocation of factors across sectors from local demand conditions. Instead, South faces an exogenously given relative price $p$, and thus (5) yields

$$
L_{1}=\frac{\mu \theta L}{(1-\mu \theta) p^{1 / \alpha}+\mu \theta} .
$$

The amount of labor allocated to the financially constrained sector 1 is decreasing in $p$ and increasing in $\theta$. Intuitively, a larger $p$ raises the value of the marginal product of labor in sector 2 , thus pulling labor away from sector 1 . Similarly, a lower $\theta$ increases the amount of capital allocated to the unconstrained sector 2 , thus again raising the marginal product of labor in that sector. When the world relative price $p$ happens to coincide with South's autarky price (i.e., when $\theta^{N}=\theta$ ), then $L_{1}$ coincides as well with the autarky allocation, that is, $L_{1}=\eta L$. But when international trade allows South to face a less depressed relative price $p$, South tilts the allocation of labor toward the unconstrained sector 2 , thus specializing in the less "financially dependent" sector. The result is intuitive: the depressed relative price $p$ under autarky indicates that South has comparative advantage in the unconstrained sector, and thus it is natural that South exports this good in the free-trade equilibrium. ${ }^{7}$

The equilibrium rental rate of the small open economy is again pinned down by the marginal product of capital in the unconstrained

\footnotetext{
${ }^{6}$ For the sake of generality, we omit the superscript $S$ when referring to Southern variables in this section. Our expressions also apply to a small open economy with $\eta / \mu>\theta>\theta^{N}$, though in that case trade integration leads to a decrease in $p$ in that economy.

${ }^{7}$ It is straightforward to show that the volume of Southern exports of good 2 is positive if and only if $\theta^{N}>\theta$. See Sec. IV and App. B for a more general proof of this result.
} 
sector. Using equations (4) and (13), we can express the real rental rate in terms of good 2 as

$$
\frac{\delta}{p}=\alpha Z\left\{\left[(1-\mu \theta)+\mu \theta p^{-1 / \alpha}\right] \frac{K}{L}\right\}^{\alpha-1},
$$

which is clearly an increasing function of $p$. It is then obvious that the real rental in terms of the numeraire good 1 is also increasing in $p$ :

$$
\delta=\alpha Z p\left\{\left[(1-\mu \theta)+\mu \theta p^{-1 / \alpha}\right] \frac{K}{L}\right\}^{\alpha-1} .
$$

The effects of trade on the rental rate of capital are tightly related to the induced changes in the sectoral capital-labor ratios. As shown above, an increase in $p$ reduces $L_{1}$ while holding constant $K_{1}$, and thus it increases $K_{1} / L_{1}$ and reduces $K_{2} / L_{2}$. It is then clear that the marginal product of capital in sector 2 (and hence $\delta / p$ ) increases when $p$ increases, which immediately implies that $\delta$ is also increasing in $p .{ }^{8}$ In sum, we have the following proposition.

Proposition 2. Trade integration raises the real rental rate of capital in the financially underdeveloped South.

The key for the result is that, by allowing South to specialize in a sector with lower financial frictions, international trade reduces the negative impact of financial underdevelopment on the rental rate of capital. In the next section we will show that this result holds in much more general environments than the one studied in our benchmark model. ${ }^{9}$

Figure 1 illustrates the beneficial effect of trade integration on the Southern rental rate of capital. The figure depicts the value of the marginal product of labor in each sector in terms of the unconstrained sector output (i.e., $\mathrm{MPL}_{1} / p$ and $\mathrm{MPL}_{2}$ ). Owing to diminishing marginal returns to labor, the schedule $\mathrm{MPL}_{1} / p$ is decreasing in the allocation of labor to sector 1 as measured from left to right, relative to the origin $O_{1}$. Similarly, the schedule $\mathrm{MPL}_{2}$ is decreasing in the allocation of labor to sector 2, as measured from right to left starting at the origin $O_{2}$. The distance between the two origins is given by the endowment of labor in South. Equation (5) then dictates that the equilibrium value of $L_{1}$ is given by the intersection of these two curves. It is then obvious that an increase in $p$ (which shifts the schedule $\mathrm{MPL}_{1} / p$ down and to the

\footnotetext{
${ }^{8}$ The counterpart of this result is that trade liberalization reduces the "premium" remuneration obtained by Southern entrepreneurs in sector 1 (i.e., $\lambda$ is decreasing in $p$ ). In fact, one can show that the total return to entrepreneurial capital $(R=\delta+\lambda \theta)$ is necessarily decreasing in $p$ as well.

${ }^{9}$ It can also be shown that trade integration necessarily raises welfare in the South (see Antràs and Caballero [2007] for a general proof of this result in our static model).
} 


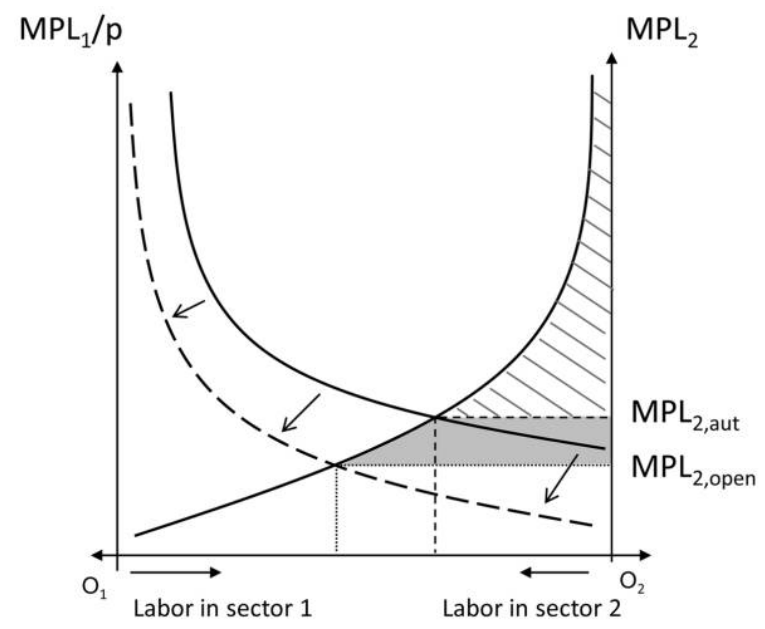

FIG. 1.-Trade integration and the rental rate of capital

left) will lead to a reduction in $L_{1}$ and an increase in $L_{2} \cdot{ }^{10}$ Because the allocation of capital is independent of $p$, the graph also depicts the effect of trade integration on the rental rate $\delta / p$. In particular, total payments to capital in sector 2 are given by the area to the right of the schedule $\mathrm{MPL}_{2}$ and above the equilibrium marginal product of labor. Because all pieces of capital obtain the same return $\delta / p$ in that sector, it is clear that the rental rate increases in an amount proportional to the shaded area in the graph. Hence, $\delta / p$ rises when $p$ rises, and a fortiori so does $\delta$. The figure also makes it clear that trade integration lowers the wage-rental ratio in South.

\section{The Cross Section of Rental Rates}

Given equation (14), we can also study the effects of an improvement in financial contractibility, that is, an increase in $\theta$, on the equilibrium rental rate of capital. This exercise is useful because it serves to characterize the cross section of rental rates across economies that trade at a common relative price $p$ but have different values of $\theta$ (e.g., North and South). Remember that in the autarky equilibrium we established that both $\delta / p$ and $\delta$ were increasing in $\theta$, and thus the rental rate was higher in North than in South. Conversely, equation (14) indicates that $\delta$ (and thus also $\delta / p$ since $p$ is given) is now decreasing in $\theta$. Hence, trade integration not only raises the real rental rate of capital in financially

\footnotetext{
${ }^{10}$ Even though the marginal product of labor in terms of good 2 falls with trade, one can show that the real wage $w / p^{1-\eta}$ will in fact increase with the increase in $p$.
} 
underdeveloped countries (proposition 1) but actually leaves that rental rate at a level that is higher than in relatively financially developed countries.

This somewhat paradoxical result can be explained as follows. Because both countries allocate some labor to each of the two sectors, the zeroprofit condition in sector 2 ensures that

$$
p=\left[\frac{\delta(\theta)}{\alpha}\right]^{\alpha}\left[\frac{w(\theta)}{1-\alpha}\right]^{1-\alpha},
$$

where the right-hand side is the unit cost in sector 2. It is then clear that in the free-trade equilibrium it can no longer be the case that an economy with a low value of $\theta$ features both depressed wages and a depressed rental rate of capital, as was the case under autarky. Moreover, a few steps of algebra show that the wage is increasing in financial development as long as $p<1$ :

$$
w=(1-\alpha) Z\left\{\left[(1-\mu \theta) p^{1 / \alpha}+\mu \theta\right] \frac{K}{L}\right\}^{\alpha} .
$$

Put differently, a small open economy with a lower $\theta$ features higher rates of return to capital "because" it has depressed wages. The depressed wage follows from the fact that, even if the aggregate capitallabor ratio $K / L$ is identical in both countries, under free trade the capital-labor ratio in both sectors is lower in the low- $\theta$ South than in the high $-\theta$ North. In sector 1 , it is lower because entrepreneurs earn higher rents in South than in North, and hence the cost of capital is higher. In sector 2, it is lower because when the economy opens to trade, South specializes in (i.e., shifts labor to) this sector, which is the capital-intensive sector of the economy. ${ }^{11}$

To see this more formally, let us develop a local proof of the effect of an increase in $\theta$ in the open economy (i.e., of a North that has an infinitesimal financial advantage over South). We can decompose the aggregate capital labor ratio, $k \equiv K / L$, into a weighted average of the sectoral capital-labor ratios, $k_{1} \equiv K_{1} / L_{1}$ and $k_{2} \equiv K_{2} / L_{2}$, with weights $\psi_{1}=L_{1} / L$ and $1-\psi_{1}$, respectively:

$$
\psi_{1} k_{1}+\left(1-\psi_{1}\right) k_{2}=k .
$$

Total differentiation of this expression yields

$$
\left(k_{2}-k_{1}\right) d \psi_{1}=\psi_{1} d k_{1}+\left(1-\psi_{1}\right) d k_{2} .
$$

\footnotetext{
${ }^{11}$ Of course, if we instead have a situation in which North has a higher aggregate capitallabor ratio, then the depressed wage result can hold even when the constrained sector's technology is relatively capital intensive. We return to this generalization later in the paper.
} 
Note that the left-hand side of (16) is positive because a higher $\theta$ is associated with specialization toward sector $1\left(d \psi_{1}>0\right)$ and because the financial constraint makes sector 1 less capital intensive than sector 2 $\left(k_{1}<k_{2}\right)$. Because the value of the marginal product of labor is equated in both sectors, $d k_{1}$ and $d k_{2}$ must have the same sign ( $p$ is held constant in the exercise), and this sign must clearly be positive to match the sign of the left-hand side of (16). In sum, we have that $d k_{1}>0$ and $d k_{2}>0$, and hence wages are higher when $\theta$ is higher. ${ }^{12}$

We can summarize the results of this section as follows. ${ }^{13}$

Proposition 3. In the free-trade equilibrium, South produces both goods and is a net importer of the "financially dependent" good 1. Furthermore, free trade does not result in factor price equalization: the wage rate is lower in South than in North $\left(w^{S}<w^{N}\right)$, whereas the rental rate of capital is higher in South than in North $\left(\delta^{S}>\delta^{N}\right)$.

\section{Trade and Capital Mobility as Complements}

As usual in international trade theory, so far we have studied scenarios in which goods can freely move across countries, but factors of production cannot. In this section we consider the implications of allowing for physical capital mobility. Following the lead of Mundell (1957), we study the interaction of capital mobility and trade integration by comparing the incentives for capital mobility with and without trade frictions in our benchmark model.

\section{A. Capital Mobility with Large Trade Frictions}

Consider first the case with trade frictions. It is obviously the case that with prohibitive trade costs for both goods, there would never be an incentive for capital to move across borders, even in the presence of factor price differences across countries. The reason is that, under those circumstances, there would not be any vehicle to repatriate rental payments from abroad. Consider then a situation in which trade in one of the two goods (say good 2) is prohibitive, whereas trade in the other good (say good 1) is costless. Without capital mobility, the equilibrium is then as described in Section II.C above. Despite the tradability of good 1, with free trade in just one good, South cannot specialize in its

\footnotetext{
${ }^{12}$ In our benchmark Cobb-Douglas model there is a straightforward alternative proof of the depressed wage mechanism: in this economy the share of labor is $1-\alpha$; hence wages are proportional to aggregate output (productivity). However, for a given $p<1$, output increases with the share of factors allocated to sector 1 , and we have shown that this share is increasing with respect to $\theta$.

${ }^{13}$ One can also show that the shadow value of cash is not equated across countries either and remains at a higher level in South than in North, i.e., $\lambda^{S}>\lambda^{N}$.
} 
comparative advantage sector and the equilibrium is identical to the autarkic one. From equation (9), it is then clear that in such a case we have $\delta^{N}>\delta^{S}$. In words, despite both countries sharing the same aggregate capital-labor ratio, the rental rate of capital is higher in North than in South.

If we then allow for physical capital mobility, rentiers in South have an incentive to move their endowment of capital to North. The counterpart of this flow of capital is a positive net import of good 1 in South in an amount equal to the rental payments of the capital stock exported from South to North. ${ }^{14}$ The amount of nonentrepreneurial capital $F^{S \rightarrow N}$ that needs to flow to North in order to ensure that $\delta^{S}$ converges up to the (unaffected) Northern rental $\delta^{N}$ is cumbersome to compute, but using (5) and imposing goods market clearing, we find that it is implicitly given by

$$
\begin{gathered}
\frac{\left\{\left(1-\mu \theta^{S}\right) \eta-[\eta+\alpha(1-\eta)] \frac{F^{S \rightarrow N}}{K}\right\}^{\alpha}\left\{1-\mu \theta^{S}-[1+\alpha(1-\eta)] \frac{F^{S \rightarrow N}}{K}\right\}^{1-\alpha}}{1-\mu \theta^{N}} \\
\times\left(\frac{\theta^{N}}{\eta \theta^{S}}\right)^{\alpha}=1 .
\end{gathered}
$$

Note that $F^{S \rightarrow N} / K$ is necessarily increasing in $\theta^{N}$ and decreasing in $\theta^{S}$. Hence, the larger the difference in financial contractibility, the larger the share of Southern capital that flows out to North. ${ }^{15}$ As a counterpart of this capital flow, South imports good 1 in an amount $M_{1}^{S}=\delta^{N} F^{S \rightarrow N}$.

This result bears some resemblance to those derived in the literature arguing that financial frictions may help explain the Lucas (1990) paradox (Gertler and Rogoff 1990; Shleifer and Wolfenzon 2002; Reinhart and Rogoff 2004; Kraay et al. 2005). In a world in which capital-scarce countries also are financially underdeveloped, our closed economy equilibrium can help rationalize why capital does not flow to those countries.

Notice that we have restricted our analysis to the case involving mobility of rentier capital. Because the return to entrepreneurial capital varies across countries, there might be an incentive for that capital to move across borders as well. Notice, however, that in order to arbitrage

\footnotetext{
${ }^{14}$ The assumption that rental payments are settled in sector 1 output is not important. In the case in which good 2 serves as the means of payment, it is still the case that some Southern rentiers decide to move their capital to North. The reason for this is that in autarky both $\delta$ and $\delta / p$ are increasing in $\theta$. Obviously, in that alternative case, South would import good 2 rather than good 1, but this is inconsequential for the substantive results here.

${ }^{15}$ If South is large enough, this (physical) capital flow has a nonnegligible effect on the rental rate $\delta^{N}$ in North. In such a case, the required capital flow $F^{S \rightarrow N}$ continues to be increasing in $\theta^{N} / \theta^{S}$, but it is quantitatively smaller (relative to South's capital).
} 
away entrepreneurial capital return differentials, it is not sufficient for entrepreneurs to simply move their physical capital abroad. Only when the movement of capital is accompanied by a movement of entrepreneurial ability, corporate governance, or the entrepreneur himself will the latter be able to capture some of the return differential. In practice, the costs involved in the movement of these additional factors may far outweigh the costs of pure physical capital mobility. Regardless of these considerations, as we argued above, the effect of $\theta$ on the return to entrepreneurial capital is ambiguous in the closed economy case, so the direction of capital flows under autarky is in general ambiguous.

\section{B. Capital Mobility with Small Trade Frictions}

We next consider the case in which there is free trade in both goods. Conceptually, this is analogous to considering a situation in which there is substantial heterogeneity in financial dependence across the set of goods that are traded in world markets. Our results in propositions 2 and 3 indicate that, with free trade, the rental rate of capital in South is higher than under autarky and also exceeds the same rental return in North, that is $\delta^{S}>\delta^{N}$. It then follows that if we allow rentiers to move their endowments across borders, capital now moves from North to South. Furthermore, because the allocation of capital to the constrained sector in South is bounded above by $\mu \theta^{S} K$, Northern capital flowing to South only increases the amount of capital employed in sector 2 (i.e., the Southern export sector).

From equations (5), (9), (14), and (12), the exact capital flow required to ensure rental rate equalization is now given by

$$
\frac{F^{N \rightarrow S}}{K}=\frac{\left(\eta-\mu \theta^{N}\right)\left(\theta^{N}-\theta^{S}\right)}{\theta^{N}(1-\eta)}
$$

and again vanishes when $\theta^{S} \rightarrow \theta^{N}$. Importantly, because the capital flow makes both countries share a common relative price $p$ and a common rental rate $\delta$, wages $w$ and the shadow price $\lambda$ are also equalized across countries. Hence, as in the classical Heckscher-Ohlin-Mundell model, free good and factor mobility leads to factor price equalization. An important difference is that our model requires both types of mobility for equalization to take place.

Our results show that, from the point of view of South, trade integration and capital inflows are complements in the sense that a process of trade integration increases the incentives for capital to flow to financially underdeveloped countries. Our benchmark model illustrates the power of this complementarity in a particularly strong way in that 
moving from autarky to free trade necessarily reverses the direction of capital flows across countries.

The complementarity between trade flows and capital mobility in our model is in sharp contrast with the substitutability present in the standard Heckscher-Ohlin model. As shown by Mundell (1957), in that model, a process of trade integration necessarily lowers the rental rate of capital in capital-scarce countries and reduces the incentives for capital to flow to those economies. Furthermore, under certain circumstances, a move toward free trade leads to factor price equalization and eliminates the incentive for capital to move to those countries altogether. Hence, in the Heckscher-Ohlin-Mundell world, trade and capital mobility are substitutes from the point of view of capital-scarce countries. As we will document in the next section, capital-scarce countries also tend to be financially underdeveloped, and this makes our opposite conclusions particularly relevant.

Although we have focused on a discussion of capital flows under autarky or free trade, our model can easily accommodate cases with intermediate trade frictions. For instance, maintaining the assumption that the numeraire good 1 is freely tradable, we can let good 2 be subject to an iceberg transport cost such that a fraction $\tau \in(0,1)$ of the good is lost in transit. Because in equilibrium South exports good 2, this is formally equivalent to North levying a tariff on Southern imports. Alternatively, we could have assumed that the trade friction is in sector 1 . This would lead to identical expressions, but the trade friction would then have effects analogous to those of an import tariff levied by South (with the tariff revenue being wasted). In either case, we can think of a reduction in $\tau$ as a reduction in transportation costs or as a trade liberalization episode. Given our assumption that South is a small open economy, the trade friction amounts to Southern producers facing relative prices equal to $p^{N}(1-\tau)$ rather than $p^{N}$ (as long as $p^{N}[1-\tau]>$ $p_{\text {aut }}^{S}$ ), and thus the trade friction $\tau$ has a monotonic effect on the relative price $p$ faced by South. Because the Southern rental rate of capital is increasing in this relative price $p$, we then obtain the following result.

Proposition 4. There exists a unique level of trade frictions $\bar{\tau} \in$ $\left(0,1-p_{\text {aut }}^{S} / p^{N}\right)$ such that, for $\tau<\bar{\tau}$, we have $\delta^{N}<\delta^{S}$, whereas for $\tau>\bar{\tau}$, we have $\delta^{N}>\delta^{S}$. Consequently, (physical) capital migrates South when $\tau<\bar{\tau}$ and North if $\tau>\bar{\tau}$.

This proposition generalizes our "reversal of capital flows" result, and it is at the core of our main result regarding the complementarity between trade and capital mobility. The particular value for the threshold integration level $\bar{\tau}$ cannot be derived in closed form, but applying the implicit function theorem to (14), we obtain that $\partial \bar{\tau} / \partial \theta^{S}<0$. In words, the lower financial development in South, the lower the amount of trade integration needed to ensure that capital flows into South when 
allowing for capital mobility. Intuitively, the wage is particularly depressed in regions with less developed financial markets, and hence the incentive for capital to flow in is particularly high.

Finally, it is worth mentioning that with positive trade frictions, it is no longer the case that trade integration and free physical capital mobility necessarily lead to factor price equalization. Even when the direction of capital flows is from North to South, the presence of trade frictions ensures that wages in South remain depressed even with frictionless capital mobility.

\section{Robustness, Generalizations, and Discussion}

Our benchmark model isolates the effects of cross-country and crosssectoral heterogeneity in financial frictions on the structure of trade and capital flows. In this section, we introduce Heckscher-Ohlin determinants of international trade into the analysis. This extension has two purposes. On the one hand, we seek to explore the robustness of our results to more general specifications of preferences and technology. On the other hand, we want to study how the standard results of the Heckscher-Ohlin-Mundell model are modified by the presence of financial frictions. For this reason, we focus for the most part on the range of parameter values for which the financial constraint binds.

\section{A. The General Model}

The model is a simple generalization of our benchmark static model. The only modifications are that we relax our strong assumptions regarding preferences and technology, we allow for cross-country variation in aggregate capital-labor ratios, and we let both countries be economically large. Our assumptions are the standard ones in the HeckscherOhlin model. On the preference side, we assume that all agents in the world have identical homothetic preferences so that we can express demand in sector 1 relative to demand in sector 2 as a general function

$\kappa(p)$ of the relative price $p$. The only restriction we place on $\kappa(p)$ is that it is nondecreasing. On the technology side, we assume that both countries have access to the same technologies to produce goods 1 and 2 and that these technologies feature constant returns to scale, continuously diminishing marginal products, and no factor intensity reversals. We denote these technologies by $F_{i}\left(K_{i}, L_{i}\right)$ and allow $F_{1}(\cdot)$ and $F_{2}(\cdot)$ to differ. Furthermore, North and South are endowed with potentially different aggregate capital-labor ratios, which we denote by $K^{N} / L^{N}$ and $K^{S} / L^{S}$, respectively. We next explore the robustness of our main results to this more general environment, which we refer to as our "general 
model." For the most part, we focus on discussing our results verbally or graphically and relegate most mathematical details to Appendix B.

\section{B. Complementarity between Trade and Capital Movements}

One might have expected that when we introduce Heckscher-Ohlin features into our framework, our complementarity result would be blurred by the standard Stolper-Samuelson theorem. In particular, it seems reasonable that if South is not just financially underdeveloped but is also relatively capital scarce, then a process of trade liberalization will lead to increased specialization in the labor-intensive sector and will push down the relative demand for capital and its equilibrium rental rate. More specifically, one might worry that our complementarity result is driven by the fact that, in the benchmark model, the unconstrained sector (which is the sector in which South has comparative advantage) is actually the relatively capital-intensive one.

Perhaps surprisingly, we next argue that as long as South has comparative advantage in the unconstrained sector, then a process of trade liberalization will increase the Southern real rental rate of capital regardless of factor intensity differences across sectors. More precisely, as long as South features a relative price $p$ under autarky lower than that in North (i.e., $p_{\text {aut }}^{S}<p_{\text {aut }}^{N}$ ), proposition 2 will continue to be valid even when the technology in sector 2 is significantly more labor intensive than that in sector 1 (or vice versa) and even when the Northern capitallabor ratio is much higher than that in South. In particular, we can state the following result.

Proposition 5. In our general model, it continues to be the case that, as long as the autarky relative price $p$ is lower in South than in North, trade integration reduces the wage-rental ratio and increases the real rental rate of capital in South. As a result, trade integration increases the incentives for capital to flow into South.

In order to see the intuition for this "anti-Stolper-Samuelson" result, it suffices to go back to figure 1. Remember that in illustrating the complementarity result through that graph, we appealed only to diminishing marginal productivity of labor in production and to the fact that trade integration was associated with an increase in $p .{ }^{16}$ In particular, the fact that production technologies were assumed symmetric in the benchmark model played no role. The key feature of our model is that, regardless of relative factor intensities, as $p$ rises, the marginal productivity of factors in the unconstrained sector rises, but only labor is re-

\footnotetext{
${ }^{16}$ Note that our assumption of homothetic preferences implies that, provided that $p_{\text {aut }}^{S}<p_{\text {aut }}^{N}$, a process of trade integration will always lead South to face a higher relative price $p$, even when South is not a small open economy. See the next subsection and App. B for more details.
} 
leased from the constrained sector. As a result, regardless of the relative capital intensity of the two sectors, an increase in $p$ reduces the capitallabor ratio in sector 2 , thereby reducing the wage-rental ratio and increasing the real rental rate of capital. ${ }^{17}$

It may be apparent to the savvy reader that the generality of our complementarity result is connected to a well-known result in the specific-factors model (see Jones 1971; Samuelson 1971), namely, that trade integration increases the real reward of the type of capital specific to the comparative advantage sector. In our model, physical capital is not sector specific, but the rents obtained by entrepreneurial capital are sector specific because of the heterogeneity in financial frictions across sectors. As a result, even though trade integration increases the marginal product of capital in sector 2, entrepreneurs are reluctant to move their capital to that sector because of the loss in rents associated with that move.

Despite these similarities, our model is quite distinct from the specificfactors model. In that model, one could obtain just about any pattern of comparative advantage and factor mobility by appropriate choices of the endowments of each type of capital as well as their assumed ease of mobility across borders. By linking the extent of capital mobility (both across sectors and across countries) to financial frictions, our model provides sharp predictions for the pattern of comparative advantage as well as for the incentives for capital to flow across borders with and without trade integration. ${ }^{18}$

\section{Comparative Advantage}

The previous subsection showed that our main complementarity result is quite general and requires only that South has comparative advantage in the unconstrained sector, in the sense that the autarky relative price $p$ is lower in South than in North. Our benchmark model satisfies this property because of the lower level of financial development in South, though one may wonder whether the result was dependent on particular functional form assumptions. More significantly, in our general model

\footnotetext{
${ }^{17}$ In contrast, in the Heckscher-Ohlin model, an increase in the relative price of the labor-intensive good leads to a move of labor and capital to that sector. Furthermore, because the capital-labor ratio of the absorbing sector is lower than that of the sector releasing factors, an increase of the wage-rental ratio (and a decrease of the real rental rate) is needed to accommodate that shift.

${ }^{18}$ For more on this, see the previous version of our model in Antràs and Caballero (2007). There, we specified a perfectly competitive three-factor model that featured the same equilibrium as our model and elaborated on the differences between our framework and a standard specific-factors model. The development of such an analogous competitive model allowed us to conclude that, in our general static model, there necessarily exist welfare gains from trade for each country, despite the presence of financial frictions.
} 
the autarky relative price $p$ is also affected by the interaction between relative factor abundance and relative factor intensity, and this complicates the relative ranking of $p_{\text {aut }}^{N}$ and $p_{\text {aut }}^{S}$. For instance, if North happens to be relatively capital abundant, so $K^{N} / L^{N}>K^{S} / L^{S}$, and the unconstrained sector happens to be relatively capital intensive, then it is theoretically possible that North would gain comparative advantage in the unconstrained sector 2, despite its more sophisticated financial system. Less trivially, if the unconstrained sector features particularly high complementarity between capital and labor relative to the constrained sector, the relative abundance of capital in North could also generate a large relative supply of good 2 in North and an associated low relative price $p$ under autarky. More formally, in Appendix B, we prove the following result.

Proposition 6. In the closed economy equilibrium of our general model, an increase in financial contractibility $\theta$ necessarily raises the relative price $p$ of the unconstrained sector. An increase in the aggregate capital-labor ratio will raise this relative price $p$ if and only if

$$
\frac{\alpha_{1}}{\left(1-\alpha_{1}\right) \sigma_{1}}-\frac{\alpha_{2}}{\left(1-\alpha_{2}\right) \sigma_{2}}>0
$$

where $\alpha_{i}$ is one minus the labor share in sector $i=1,2$ and $\sigma_{i}$ is the elasticity of substitution between capital and labor in the same sector $i$, that is, $\partial\left(\ln K_{i} / L_{i}\right) / \partial \ln (w / \rho)$, where $\rho=\left[F_{i}\left(K_{i}, L_{i}\right)-w L_{i}\right] / K_{i}$.

The first statement of the proposition confirms that the negative (partial) correlation between $p$ and $\theta$ identified in our benchmark model remains valid for general neoclassical production functions and general homothetic preferences. The intuition for the generality of this result is most easily conveyed through graphical analysis (see App. B for mathematical details). Figure 2 depicts the production possibility frontier (PPF) for North and South when the two countries differ only in their level of $\theta$. As long as the ratio of sector 2 output to sector 1 output is high, the financial constraint (3) will not bind and the two PPFs will coincide. Nevertheless, for a high enough ratio $Y_{1} / Y_{2}$, the financial constraint will bind and the Southern PPF is obtained by bowing the Northern one in, in a manner that makes the slope of the PPF lower in South for any ratio $Y_{1} / Y_{2}$ in that region. Coupled with our assumption of identical homothetic preferences, this necessarily implies that the relative autarky price $p$ must be lower in South than in North.

This theoretical result is consistent with the findings of Manova (2008), who provides empirical evidence suggesting that, controlling for several factors, financially developed countries indeed tend to feature disproportionately high export volumes in the set of industries that Rajan and Zingales (1998) identified as being financially dependent 


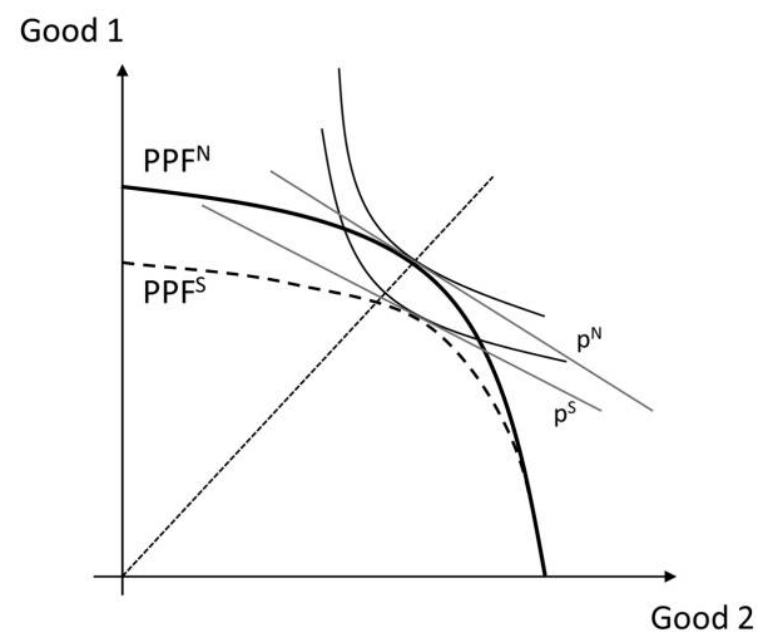

Fig. 2.-Effect of $\theta$ on autarky relative price $p$

(namely, sectors in which firms have a relatively high fraction of total capital expenditures not financed by internal cash flow).

The combination of propositions 5 and 6 suggests that our main complementarity result in the benchmark model will continue to hold in the general model whenever differences in capital-labor ratios between financially developed and financially underdeveloped countries are small or whenever the term in the left-hand side of (17) is small. In practice, however, financially developed countries tend to be significantly capital abundant relative to financially underdeveloped countries. In Manova's (2008) data set, for instance, the cross-country correlation between a standard measure of financial development and physical capital per capita is positive and high (0.678).$^{19}$

As mentioned above and as captured by condition (17) in proposition 6 , in the presence of aggregate capital-labor ratio differences between North and South, the autarky relative price $p$ could actually be lower in the capital-abundant North if the constrained sector featured a particularly high labor share or a particularly low elasticity of substitution between capital and labor. As explained in more detail in Appendix C, none of these conditions seems to find much support, at least in U.S.

${ }^{19}$ This corresponds to the correlation between the amount of credit extended by banks and other nonbank financial intermediaries to the private sector divided by GDP averaged over 1980-89 and the log of the average physical capital stock per capita in a given country during the same period. 
data. ${ }^{20}$ In particular, we compute Rajan and Zingales's measure of financial dependence at the three-digit standard industrial classification (SIC) level, averaged over the period 1980-89, and we correlate it with (a) the labor share in that industry $\left(1-\alpha_{i}\right) ;(b)$ an estimate of the elasticity of substitution between capital and labor in that sector $\left(\sigma_{i}\right)$; and $(c)$ the term $\alpha_{i} /\left[\left(1-\alpha_{i}\right) \sigma_{i}\right]$, which is the relevant one according to theory. Appendix $\mathrm{C}$ contains more details on the construction of these variables. We find very low correlations between financial dependence and each of these variables: the particular values are $0.034,0.012$, and -0.026 , respectively.

We conclude from these findings, together with those of Manova (2008), that financially underdeveloped countries appear to indeed gain comparative advantage in relatively financially unconstrained sectors. This implies that it is natural to associate trade integration in financially underdeveloped countries with an increase in the relative price $p$, and in light of proposition 5, we can conclude that trade integration increases the incentives for capital to flow to these financially underdeveloped countries.

\section{Direction of Capital Flows with Free Trade}

We next consider under which conditions the ranking of factor prices derived in proposition 3 survives in our general model. Note that whenever both North and South produce good 2 in equilibrium, the zeroprofit condition in that sector ensures

$$
p=c_{2}\left(\delta^{j}, w^{j}\right) \text { for } j=N, S,
$$

where $c_{2}(\cdot)$ is a general neoclassical unit cost function and is thus increasing in both arguments. Hence, as in our benchmark model and in contrast to the autarkic case, with free trade in good 2 it must be the case that either $w^{S}>w^{N}$ or $\delta^{S}>\delta^{N}$. However, for a general constant returns to scale technology in sector 2 , we must also have that

$$
\frac{w^{j}}{\delta^{j}}=\vartheta\left(\frac{K_{2}^{j}}{L_{2}^{j}}\right) \quad \text { for } j=N, S,
$$

where $\vartheta(\cdot)$ is necessarily increasing in $K_{2}^{j} / L_{2}^{j}$. Equations (18) and (19) combined imply that the ranking of factor prices is necessarily as derived in proposition 3 provided that North operates the technology in the

\footnotetext{
${ }^{20}$ When production functions are not Cobb-Douglas or constant elasticity of substitution, differences in financial development across countries could generate variation in the parameters $\alpha_{i}$ and $\sigma_{i}$ across countries. Data limitations, however, preclude us from performing similar tests for other countries.
} 
unconstrained sector 2 at a higher capital-labor ratio than South does, $K_{2}^{N} / L_{2}^{N}>K_{2}^{S} / L_{2}^{S}$, which is an empirically likely scenario.

In our benchmark model, the condition $K_{2}^{N} / L_{2}^{N}>K_{2}^{S} / L_{2}^{S}$ is ensured by the fact that North specializes in the constrained sector 1, which operates at an inefficiently low capital-labor ratio. ${ }^{21}$ In Appendix B, we confirm that this is not an artifact of our Cobb-Douglas assumptions: for general homothetic preferences and general symmetric production functions with constant returns to scale and diminishing marginal products, we obtain that capital intensity will be lower in the constrained sector 1 than in the unconstrained sector 2, and with free trade, the rental rate is higher in South than in North. ${ }^{22}$ This allows us to make the following conclusion.

Proposition 7. In our general model, whenever sectors differ only in financial dependence and North is at least as relatively capital abundant as South, trade integration not only raises the real rental rate of capital in South but leaves this rental rate at a higher level in South than in the more financially developed North.

Whenever sectors differ not only in financial dependence but also in capital intensity, it is no longer the case that free trade necessarily results in a larger rental rate in South (see App. B for details). For instance, if the unconstrained sector happens to be particularly labor intensive and North and South have similar aggregate capital-labor ratios, then it could well be the case that $\delta^{N}>\delta^{S}$ with free trade. These conditions appear, however, to be counterfactual given the empirical evidence reviewed in the last subsection. In Appendix B, we also show that for general asymmetric production functions, the Southern rental rate under free trade will always exceed the Northern one provided that North is sufficiently capital abundant relative to South. ${ }^{23}$

\footnotetext{
${ }^{21}$ An interesting implication of this result is that, in our benchmark model, Northern exports are less capital intensive than Northern imports. More generally, as long as North and South differ only in their level of financial development and production technologies are sufficiently symmetric, North is necessarily a net importer of capital services embodied in goods. Hence, credit constraints may provide an explanation for the so-called Leontief paradox (see Wynne [2005] for more on this).

${ }^{22}$ We have assumed throughout that the financial constraint binds both in North and in South. It is straightforward to show that if the constraint does not bind in North, then trade integration continues to raise the rental rate of capital in South, but the model delivers factor price equalization (and the elimination of Southern entrepreneurial rents) with free trade.

${ }^{23}$ It should be clear, however, that the likelihood of a reversal in the direction of capital movements brought about by trade integration is not necessarily higher when differences in aggregate capital-labor ratios are high, because these differences might also induce an autarky rental rate in South that exceeds the Northern one.
} 
E. Relationship with Other Notions of Complementarity

In the introduction we were careful to define our notion of complementarity between trade and capital mobility in terms of the incentives for capital to flow to a particular country. According to our definition, in the Heckscher-Ohlin model, trade and capital movements are substitutes from the point of view of capital-scarce economies, whereas in our model they are complements from the point of view of financially underdeveloped economies.

The substitutability between trade and capital movements in the Heckscher-Ohlin model is also often understood in other manners. First, substitutability is associated with the prediction of the HeckscherOhlin model that capital movements across countries tend to reduce trade flows across countries. In our model, capital movements can increase or decrease trade flows depending on the level of trade costs. As proposition 4 indicates, when trade frictions are large, capital will flow from South to North. Furthermore, since the allocation of capital to the constrained sector is unaffected by trade or capital flows across countries, this capital movement will necessarily expand the comparative disadvantage sector in North, whereas it will contract the comparative advantage sector in South, thus tending to reduce trade flows across countries. Conversely, when trade frictions are small, capital will instead flow from the comparative disadvantage sector in North to the comparative advantage sector in South, hence increasing trade flows across countries. This type of complementarity generated by our model is closer in spirit to that in Markusen (1983), but it is important to emphasize that it arises only when trade frictions are low as opposed to our preferred notion of complementarity, which holds more generally.

Second, trade and capital movements are sometimes thought to be substitutes when they act as alternative means to bring about factor price equalization (FPE) in the world. In his seminal contribution, Mundell (1957) stressed the fact that not only is it true that trade in goods can bring about FPE and eliminate the incentive for capital to flow across countries, but it is also the case that capital movements across countries will arbitrage away factor cost differences across countries and will eliminate the need to trade across countries. Again, our model does not feature this type of substitutability. As argued earlier, whenever financial constraints bind, FPE is reached in our model only when there is free mobility of goods across countries and free mobility of rentier capital across countries. Hence, neither trade nor capital movements can substitute for the other in bringing about FPE. 


\section{The Complementarity with Capital Accumulation}

Up to now we have studied the interaction of financial frictions and trade integration in shaping the desired location of physical capital. We concluded that when trade frictions are significant, there is an incentive for physical capital to migrate from the financially underdeveloped South to the financially developed North, whereas the opposite is true when trade is frictionless. In this section we introduce saving and capital accumulation decisions in order to show how our main complementarity result carries over to intertemporal decisions.

As a corollary, by modeling the net capital flows implications of our view, we are also able to connect with the "global imbalances" literature, which attempts to explain the large capital flows from South to North observed in recent years. The main substantive conclusion that emerges from the analysis below is that protectionism could exacerbate rather than alleviate these imbalances if financial factors are important determinants of trade patterns.

\section{A. A Dynamic Model}

Consider the following dynamic model, which integrates a variant of the single-good framework of Caballero et al. (2008) with the static international trade model developed in the previous sections.

Time evolves continuously. Infinitesimal agents are born at a rate $\phi$ per unit of time and die at the same rate; population mass is constant and equal to $L$. All agents are endowed with one unit of labor services, which they supply inelastically to the market. ${ }^{24}$ Agents save all their income and consume only when they (are about to) die. ${ }^{25}$ Thus, if $W_{t}^{j, i}$ denotes the savings accumulated by agents of type $i=e$ (entrepreneurs) and $i=r$ (rentiers) in country $j$ up to date $t$, then aggregate consumption for each of these groups at time $t$ is $\phi W_{t}^{j, i}$. This aggregate consumption is allocated across the different goods according to the instantaneous utility given by (1) for given equilibrium prices and is subject to the budget constraint

$$
\phi W_{t}^{j, i}=C_{1 t}^{j, i}+p_{t}^{j} C_{2 t}^{j, i} .
$$

Physical capital is tradable and is the only store of value. We assume that the initial stock of capital is equal to $K_{0}^{j}$ and that new physical

\footnotetext{
${ }^{24}$ To simplify matters, we do not distinguish between workers and capitalists in this section. Our previous results on $w, \delta$, and $\lambda$ can be interpreted as applying to the different components of an agent's income.

${ }^{25}$ This can be interpreted as agents saving to provide for their long retirement. Caballero et al. (2008) show that the crucial features of the equilibrium described below survive to more general overlapping generation structures, such as that in Blanchard (1985) and Weil (1989).
} 
capital can be produced one to one with a nontradable final good that combines goods 1 and 2 according to the utility aggregator in (1). As a result, the relative price of capital is equal to the ideal price index, that is, $\left(p_{t}^{j}\right)^{1-\eta}$. For simplicity, we rule out any capital depreciation. ${ }^{26}$

Entrepreneurs are born as such, and at any given instant they constitute a share $\mu$ of the population. As in the static model, they naturally specialize in sector 1. Entrepreneurial rents are not capitalizable (i.e., they cannot be used as a store of value). This is consistent with our formulation in Appendix A, where these rents stem from the inalienability of the human capital of entrepreneurs. Note that the existence of entrepreneurial rents implies that entrepreneurs (on average) accumulate more savings than nonentrepreneurs over their life span, and hence their share of wealth (i.e., capital) in the economy is no longer given by the parameter $\mu$. Let us denote this share by $\tilde{\mu}_{t}^{j}=K_{t}^{j, e} / K_{t}^{j}$, where $K_{t}^{j, e}$ is the amount of capital owned by entrepreneurs at any instant $t$.

At any point in time, factor prices are determined exactly as in the static model developed above with $\tilde{\mu}_{t}^{j}$ replacing $\mu$. Nevertheless, in this dynamic model, physical capital plays a dual role as a productive factor and also as a store of value. Capital flows will be the mechanism by which the claims on this store of value are traded across borders, and the key price that determines the direction of these capital flows is the interest rate $r$ in each country before opening the capital account. We turn next to the determination of interest rates.

Let $q_{t}^{j}$ denote the value for a rentier of holding one unit of capital in country $j=N, S$ at any instant $t$. In equilibrium, $q_{t}^{j}$ is also the market price of a unit of capital, that is, $q_{t}^{j}=\left(p_{t}^{j}\right)^{1-\eta}$, since (surviving) agents spend all their income in buying capital and rentiers are always the marginal buyers. The return on holding a unit of capital is then equal to the dividend-price ratio $\delta_{t}^{j} / q_{t}^{j}$ plus the capital gain $\dot{q}_{t}^{j} / q_{t}^{j}$ or

$$
r_{t}^{j}=\frac{\delta_{t}^{j}}{\left(p_{t}^{j}\right)^{1-\eta}}+(1-\eta) \frac{\dot{p}_{t}^{j}}{p_{t}^{j}}
$$

Aggregate savings of each group (entrepreneurs and rentiers) decrease with consumption and increase with labor income, entrepreneurial rents (if any), and the return on accumulated savings:

$$
\dot{W}_{t}^{j, r}=-\phi W_{t}^{j, r}+(1-\mu) w_{t}^{j} L+r_{t}^{j} W_{t}^{j, r},
$$

${ }^{26}$ In a previous version of the model (Antràs and Caballero 2007), we assumed that the stock of physical capital was fixed, as in Caballero et al. (2008). This led to a distinct determination of the relative price of capital but to the same qualitative results as those derived below. 


$$
\dot{W}_{t}^{j, e}=-\phi W_{t}^{j, e}+\mu w_{t}^{j} L+\lambda_{t}^{j} \theta^{j} \tilde{\mu}_{t}^{j} K_{t}^{j}+r_{t}^{j} W_{t}^{j, e} .
$$

With a closed capital account, it must be the case that aggregate savings equal the value of the capital stock at all times:

$$
W_{t}^{j, r}+W_{t}^{j, e}=q_{t}^{j} K_{t}^{j}=\left(p_{t}^{j}\right)^{1-\eta} K_{t^{*}}^{j}
$$

Combining (23) and (20) and using the sum of (21) and (22), we have

$$
\phi\left(W_{t}^{j, r}+W_{t}^{j, \epsilon}\right)+\left(p_{t}^{j}\right)^{1-\eta} \dot{K}_{t}^{j}=\delta_{t}^{j} K_{t}^{j}+w_{t}^{j} L+\lambda_{t}^{j} \theta^{j} \tilde{\mu}_{t}^{j} K_{t}^{j} \equiv Y_{t}^{j},
$$

where the left-hand side measures the sum of country $j$ 's aggregate consumption and investment at any instant $t$, and the right-hand side measures aggregate income and output $Y_{t}^{j}$.

Equations (20)-(23) describe the dynamic evolution of the economy, together with the expressions for factor prices and the relative price $p_{t}^{j}$ derived in previous sections with $\tilde{\mu}_{t}^{j}$ replacing $\mu$. We hereafter focus on exploring the steady state of the benchmark model developed in Section II, which allows for a simple analytic illustration of our results. ${ }^{27}$ In Appendix D, we show that regardless of the initial value of $K_{0}^{j}$ and as long as $\mu \theta^{j}<\eta$ (i.e., assumption 1 ), the economy will converge to a steady state in which $K_{t}^{j}$ and $\tilde{\mu}_{t}^{j}$ are constant (implying that $p_{t}^{j}, w_{t}^{j}, \delta_{t}^{j}$, and $\lambda_{t}^{j}$ are constant as well). Furthermore, in Appendix D, we show that $\tilde{\mu}^{j}$ necessarily settles at a value larger than $\mu$ but lower than $\eta / \theta^{j}$, and hence financial constraints bind even in the long run. Intuitively, although entrepreneurs obtain a higher income period by period (thus leading to $\tilde{\mu}^{j}>\mu$ ), the finite-horizon nature of our model implies that the distribution of wealth remains nondegenerate. We also show in Appendix $\mathrm{D}$ that $\tilde{\mu}^{j}$ is a function of factor prices, which, remember, are themselves functions of $\tilde{\mu}^{j}$. These interactions between equilibrium factor prices and the tightness of the financial constraint complicate the mechanics of the model, but as illustrated below, the analysis remains tractable.

We next compute the equilibrium steady-state interest rate in our benchmark model with and without free trade. Setting $\dot{p}_{t}^{j}=0$ in equation (20) and dropping time subscripts, we obtain

$$
r^{j}=\frac{\delta^{j}}{\left(p^{j}\right)^{1-\eta}},
$$

and thus the steady-state interest rate naturally equals the rental rate of capital in terms of the composite good from which physical capital is made. In the static model, we demonstrated that the autarky real rental rate of capital is depressed in the financially underdeveloped South and

\footnotetext{
${ }^{27}$ See Antràs and Caballero (2009) for a fuller exploration of our dynamic framework.
} 
that the Southern real rental increases with a process of trade integration with a more financially developed North. Our dynamic model features capital accumulation, and one might worry that these results might be overturned by an endogenously lower aggregate capital-labor ratio in South under autarky and by an endogenous increase in the Southern capital-labor ratio following trade liberalization. Although our dynamic model can feature these endogenous responses of the aggregate capitallabor ratio, we next show that our main complementarity result continues to hold in the steady state.

To see this, consider first the case in which North and South are closed to international trade. Combining equations (8), (9), (11), and (15) together with (20), (23), and (24)—while setting $\dot{p}_{t}^{j}=\dot{K}_{t}^{j}=0$ yields

$$
\frac{K_{\text {aut }}^{j}}{L}=\left(\frac{Z}{\phi}\right)^{1 /(1-\alpha)}\left(\frac{\tilde{\mu}_{\text {aut }}^{j} \theta^{j}}{\eta}\right)^{\alpha \eta /(1-\alpha)}\left(\frac{1-\tilde{\mu}_{\text {aut }}^{j} \theta^{j}}{1-\eta}\right)^{\alpha(1-\eta) /(1-\alpha)}
$$

and

$$
r_{\text {aut }}^{j}=\phi \alpha \frac{1-\eta}{1-\tilde{\mu}_{\text {aut }}^{j} \theta^{j}},
$$

where $\tilde{\mu}_{\text {aut }}^{j}$ is the autarky steady-state share of capital in the hands of entrepreneurs in country $j$. We show in Appendix D that although the expression for $\tilde{\mu}_{\text {aut }}^{j}$ is complicated, the term $\tilde{\mu}_{\text {aut }}^{j} \theta^{j}$ is necessarily an increasing function of $\theta^{j}$ and satisfies $\tilde{\mu}_{\text {aut }}^{j} \theta^{j}<\eta$. As a result of this, the autarkic capital-labor ratio is an increasing function of $\theta^{j}$ and is thus higher in North than in South. In spite of this, equation (27) indicates that, as in our static model, the autarkic real rental rate-and thus the interest rate-continues to be an increasing function of $\theta^{j}$, which implies that South experiences a capital outflow if it integrates to global capital markets when trade frictions are large.

The low interest rate in South reflects the fact that the rental capital income, the only capitalizable income in the economy, is depressed by the financial friction. In this dynamic version of the model, financial frictions also lower the steady-state value of the capital-labor ratio, but the latter effect is a dominated one in shaping the determination of the rental rate of capital.

We can contrast this autarky result with the polar opposite case in which trade is frictionless. Plugging the equilibrium values of factor prices under free trade into (25) and using (23) and (24) yields

$$
\frac{K_{\mathrm{open}}^{j}}{L}=\left\{\frac{Z}{\phi} \frac{\left[\tilde{\mu}_{\mathrm{open}}^{j} \theta^{j}+\left(1-\tilde{\mu}_{\mathrm{open}}^{j} \theta^{j}\right) p^{1 / \alpha}\right]^{\alpha}}{p^{1-\eta}}\right\}^{1 /(1-\alpha)}
$$


and

$$
r_{\mathrm{open}}^{j}=\phi \alpha \frac{p^{1 / \alpha}}{\tilde{\mu}_{\mathrm{open}}^{j} \theta^{j}+\left(1-\tilde{\mu}_{\mathrm{open}}^{j} \theta^{j}\right) p^{1 / \alpha}},
$$

where $\tilde{\mu}_{\text {open }}^{j}$ is the steady-state share of capital in the hands of entrepreneurs under free trade. Although the equation defining $\tilde{\mu}_{\text {open }}^{j}$ is also complicated, we show in Appendix D that $\tilde{\mu}_{\text {open }}^{j} \theta^{j}$ is again necessarily increasing in $\theta^{j}$ and is also decreasing in $p$. Inspection of (29) reveals that this in turn implies that the steady-state interest rate is increasing in $p$ and decreasing in $\theta^{j}$. In words, a process of trade liberalization (an increase in $p$ ) raises the interest rate in South to the point that South actually experiences capital inflows if it integrates to global capital markets when trade is free. Hence, in analogy to propositions 2 and 5, we have the following result.

Proposition 8. Trade integration raises the interest rate in the financially underdeveloped South. Furthermore, with free trade, the interest rate is higher in South than in North, whereas the converse is true under autarky.

The logic behind the complementarity between trade and capital flows is related to that in the static model. By specializing in the unconstrained sector, rentiers' capital in South benefits from a larger amount of labor allocated to the unconstrained sector and thus earns higher returns. Furthermore, with free trade, rentier capital ends up working with a disproportionate amount of labor in economies with lower credit multipliers, and this translates into disproportionately large returns. As a result, a larger share of capital income is in the form of capitalizable rents and the return to financial capital is higher. ${ }^{28}$

We next turn to studying intermediate levels of openness, which correspond to situations with varying degrees of international specialization.

\footnotetext{
${ }^{28}$ An additional feature that emerges in the dynamic model is that trade liberalization generates endogenous changes in the tightness of the credit constraint. In App. D, we show that $\tilde{\mu}_{\text {open }}^{j}<\tilde{\mu}_{\text {aut }}^{j}$ (since trade lowers $\lambda^{S}$ ), and hence the share of capital in the hands of entrepreneurs is lower in the free-trade equilibrium than under autarky. By allowing the economy to specialize in the sector with less financial constraints, entrepreneurial rents are eroded and wealth inequality is reduced in the long run. Naturally, this implies that, contrary to our static model, the allocation of capital across sectors will not remain unaffected by a process of trade liberalization. To be precise, the static model in Sec. II captures only the "impact effect" of trade opening on factor prices. As the economy transitions to the new steady state, however, the fraction of capital in sector 1 gradually falls and that in sector 2 increases. It is straightforward to verify that, in our benchmark model, these endogenous changes in $\tilde{\mu}$ lead to a gradual tightening of credit constraints along the transition, which generates further increases in the real rental rate of capital. Nevertheless, real consumption can be shown to decrease along the transition, and hence the welfare gains from trade liberalization are much less clear-cut than in the static model. See Chesnokova (2007) for a related point.
} 
B. An Application: Protectionism Backfires

Protectionist proposals are a standard policy reaction to the so-called global imbalances that have characterized the global economy in recent years. The rationale for these proposals is that by raising trade barriers in North, the magnitude of trade surpluses in South must decline. We argue in this subsection that if the global imbalances are an equilibrium response to heterogeneous degrees of financial development across the world, protectionism may exacerbate rather than reduce them. We illustrate the reason behind our warning by showing that the pre-integration North-South interest rate spread, which is the main factor behind the direction of capital flows in our model, rises with trade frictions.

Let us extend the interest rate expression in (29) to cases of intermediate levels of trade frictions. As in Section III.B, we consider situations in which sector 1's output can be freely tradable, whereas a fraction $\tau \in(0,1)$ of sector 2's output melts in transit when shipped across countries. For simplicity, we also maintain the assumption that South is a small open economy. As a result, the relative price in South is $p^{N}(1-\tau)$ and the steady-state interest rate in each country becomes

$$
\begin{aligned}
& r^{N}=\phi \alpha \frac{\left(p^{N}\right)^{1 / \alpha}}{\tilde{\mu}^{N} \theta^{N}+\left(1-\tilde{\mu}^{N} \theta^{N}\right)\left(p^{N}\right)^{1 / \alpha}}, \\
& r^{S}=\phi \alpha \frac{\left[p^{N}(1-\tau)\right]^{1 / \alpha}}{\tilde{\mu}^{S} \theta^{S}+\left(1-\tilde{\mu}^{S} \theta^{S}\right)\left[p^{N}(1-\tau)\right]^{1 / \alpha}} .
\end{aligned}
$$

Notice that even for a common share of entrepreneurs $\mu$ in both countries, the share of entrepreneurial wealth in total wealth differs across countries $\left(\tilde{\mu}^{N} \neq \tilde{\mu}^{S}\right)$. An increase in $\tau$ affects the difference $r^{N}-r^{S}$ through a direct effect apparent in the formula for $r^{S}$ above, as well as through an indirect effect working through the steady-state value of $\tilde{\mu}^{S}$. It turns out, however, that both effects work in the same direction, and we can establish that, for a given $p^{N}$, the difference $r^{N}-r^{S}$ is strictly increasing in $\tau \cdot{ }^{29}$ Furthermore, our previous results allow us to make the following conclusion.

Proposition 9. There exists a unique level of trade frictions $\tilde{\tau} \in$ $\left(0,1-p_{\text {aut }}^{S} / p^{N}\right)$ such that, for $\tau<\tilde{\tau}$, we have $r^{N}<r^{S}$, whereas for $\tau>\tilde{\tau}$, we have $r^{N}>r^{s}$. Consequently, savings flow to South when $\tau<\tilde{\tau}$ and to North if $\tau>\tilde{\tau}$.

This result is analogous to proposition 4, now applied to capital flows. To see its implication, suppose that the initial level of trade frictions is

\footnotetext{
${ }^{29}$ It is clear from inspection of the formula for $r^{S}$ that the direct effect of $\tau$ on $r^{S}$ is negative. Furthermore, in App. D, we show that $\tilde{\mu}^{S}$ is decreasing in the relative price faced by South. A larger $\tau$ then increases $\tilde{\mu}^{S}$ and hence further reduces $r^{S}$ (since in our benchmark model $r^{S}$ is decreasing in $\tilde{\mu}^{S} \theta^{S}$ for a given relative price $p$ ).
} 
$\tau_{0} \geq \tilde{\tau}$ so that $r^{N} \geq r^{S}$. Then financial integration leads to capital outflows from South to North, a situation that captures the current scenario between emerging Asia and the United States. In fact, in our model with no adjustment costs of capital, financial integration would lead to an instantaneous capital flight that would lead to equalization of the interest rate (and thus the marginal product of capital) in both countries.

We now want to compare the impact of financial integration for different values of the trade friction $\tau \geq \tilde{\tau}$. It is clear from the above discussion that the larger $\tau$ is, the larger the gap $r^{N}-r^{s}$. Because of diminishing returns to capital, it then follows that the initial capital outflow (or trade surplus) in South will be larger the larger $\tau$ is. ${ }^{30}$ That is, protectionism backfires (if the goal is to reduce North's trade deficits).

In our derivations we have treated South as small relative to North, but it should be apparent that our substantive results do not depend on this assumption. The main significant difference is that, in the model with two large regions, financial integration also reduces the interest rate in North, thus reducing the size of the capital movements needed to equalize interest rates.

\section{An Application and Extension: High Saving Rate in Regions of South}

The implication that regions in South that are more open to trade are more prone to receive net capital inflows may appear as counterfactual when comparing Asia and Latin America. The economies in the former region are at least as open as those in the latter, but they typically run current account surpluses that are significantly larger than those of Latin American economies. However, there is no contradiction once one also considers that Asian economies have much higher saving rates.

Our dynamic model is flexible enough to accommodate such situations. In particular, suppose that South is split between high- and lowsaving regions-for example, Asia and Latin America, respectively. Because consumption in any instant is equal to a fraction $\phi$ of wealth, a natural way to capture this different propensity to consume is to have

$$
\phi^{S, \text { Asia }}<\phi^{N}<\phi^{S, \mathrm{LA}} .
$$

If all countries in South have identical financial markets, endowments,

\footnotetext{
${ }^{30}$ For simplicity, we focus here on a comparison of the impact effect of financial integration for different values of $\tau$. In Antràs and Caballero (2009), we further characterize the transitional dynamics following financial integration.
} 
technology, and instantaneous utility functions at the time of death, then it follows that before opening the capital account, we have

$$
r^{S, \mathrm{Asia}}=\frac{\phi^{S, \mathrm{Asia}}}{\phi^{S, \mathrm{LA}}} r^{S, \mathrm{LA}}<r^{S, \mathrm{LA}}
$$

More generally, high-saving countries in South need to be more open to trade than low-saving countries in order to experience net capital inflows. ${ }^{31}$

\section{Final Remarks}

The main message of this paper is that when variation in financial development and financial dependence are significant determinants of comparative advantage, trade and capital flows become complements in financially underdeveloped countries. This complementarity contrasts with the substitutability that arises for capital-scarce countries in the standard Heckscher-Ohlin-Mundell framework and has important practical implications. For example, it indicates that deepening trade liberalization in South raises its ability to attract foreign capital. At the global level, it implies that protectionist policies aimed at reducing the so-called global imbalances may backfire and exacerbate them. And while we do not analyze the normative aspects of liberalization processes, our framework hints that it is important for developing economies to liberalize trade before the capital account if capital outflows are to be averted.

Our complementarity follows from the fact that trade liberalization decouples the process of labor allocation from local demand conditions. In this context, a financially underdeveloped country is able to allocate a disproportionate number of workers in sectors in which financial frictions are less severe, thereby increasing the marginal product of capital and its equilibrium rental rate. Although we initially derived this result for the case in which South is a small open economy and preferences and technologies are Cobb-Douglas, we later demonstrated that the result is general. In particular, in a world in which countries differ only in financial development and sectors differ only in financial dependence, trade integration necessarily reduces (and actually overturns) the gap between the real return to capital in North and South. Furthermore, even after we introduce Heckscher-Ohlin determinants of

\footnotetext{
${ }^{31}$ Our model offers an alternative explanation for Latin America attracting larger net capital inflows than Asia despite being less open to trade. In particular, just as in our static model, the amount of trade integration needed to ensure net capital inflows into South is lower the lower financial development is in South. Hence, the observed patterns are also consistent with Latin America being less financially developed than Asia.
} 
trade, our complementarity result continues to hold under empirically plausible conditions.

\section{Appendix A}

\section{Microfoundations of the Financial Constraint}

In the text, we simply imposed the assumption that $B^{i} \leq(\theta-1) K^{i}$ for some constant $\theta>1$, where $B^{i}$ is the amount of capital rented by entrepreneur $i$, and $K^{i}$ is $i$ s capital endowment. In this appendix, we provide a simple microfoundation for this assumption, which builds on limited commitment on the part of entrepreneurs, along the lines of Aoki et al. (2006).

In particular, assume that the entrepreneur can always walk away from the project before production occurs (but after investment has taken place) and renege on all debt obligations in doing so. Suppose that the human capital of the entrepreneur is necessary for production to occur. If the entrepreneur refused to put his or her skills to use after obtaining the funds from investors, then revenue would be zero (human capital is inalienable) and all that investors could recoup is a fraction $\varphi \in(0,1)$ of the installed capital, that is, $\varphi\left(K^{i}+\right.$ $\left.B^{i}\right)$. Suppose that investors were allowed to rent this saved collateral in sector 2 , which would yield them a payoff of $\delta \varphi\left(K^{i}+B^{i}\right)$. We can think of $\varphi$ as our new primitive index of financial development. Regardless of the value of $\varphi$, efficiency dictates that the entrepreneur does not walk away and carries out production; but if lenders have weak bargaining power, the entrepreneur is able to use the threat of withholding his or her human capital services to renegotiate the terms of the loan. With full bargaining power, the payoff to lenders can be pushed all the way down to $\delta \varphi\left(K^{i}+B^{i}\right)$. Foreseeing this ex post renegotiation, investors lend to entrepreneurs only if their payoff is at least as large as the return they could obtain in the unconstrained sector 2 , which is $\delta B^{i}$. The participation constraint of investors hence imposes that $\delta B^{i} \leq \delta \varphi\left(K^{i}+B^{i}\right)$ or

$$
B^{i} \leq \frac{\varphi}{1-\varphi} K^{i}
$$

By setting $\theta=1 /(1-\varphi)>1$, we have the exact same formulation as in the text, with a larger $\theta$ being associated with a larger collateral value of capital (larger $\varphi)$.

We can also consider an alternative formulation in which the collateral value of capital is zero, but lenders (rentier capitalists) are not completely unable to produce in sector 1. In particular, suppose that if the entrepreneur walked away, rentiers could use the installed capital to produce a fraction $\varphi$ of sector 1's output. In this formulation, $\varphi$ is negatively related to the complexity of production in sector 1 . The outside option of lenders in this case would be, for the benchmark model,

$$
\pi^{R}=\max _{L}\left\{\varphi Z\left(K^{i}+B^{i}\right)^{\alpha}(L)^{1-\alpha}-w L\right\}=\alpha \varphi Z\left[\frac{(1-\alpha) \varphi Z}{w}\right]^{(1-\alpha) / \alpha}\left(K^{i}+B^{i}\right),
$$


and with full bargaining power on the part of entrepreneurs, the participation constraint for rentiers would now be

$$
\delta B^{i} \leq \alpha \varphi Z\left[\frac{(1-\alpha) \varphi Z}{w}\right]^{(1-\alpha) / \alpha}\left(K^{i}+B^{i}\right)
$$

In terms of the notation used in the text, this formulation implies

$$
\theta-1=\frac{\alpha \varphi Z\{[(1-\alpha) \varphi Z] / w\}^{(1-\alpha) / \alpha}}{\delta-\alpha \varphi Z\{[(1-\alpha) \varphi Z] / w\}^{(1-\alpha) / \alpha}}
$$

Notice that the credit multiplier $\theta$ is now a function of factor prices, but because firms take these prices as exogenous, firm behavior is identical to that in the text. The main difference is that, in solving for the general equilibrium, one has to be careful in acknowledging the dependence of $\theta(w, \delta)$ on $w$ and $\delta$. An implication of the analysis is that now trade affects the tightness of the constraint.

Despite these nuances, our main result on the complementarity between trade integration and net capital inflows in South is robust to this more general formulation of the benchmark model. To see this, consider first the equilibrium of a small open economy, where remember that

$$
\begin{aligned}
& w=(1-\alpha) Z\left(\left\{[1-\mu \theta(w, \delta)] p^{1 / \alpha}+\mu \theta(w, \delta)\right\} \frac{K}{L}\right)^{\alpha}, \\
& \delta=\alpha Z p^{1 / \alpha}\left(\left\{[1-\mu \theta(w, \delta)] p^{1 / \alpha}+\mu \theta(w, \delta)\right\} \frac{K}{L}\right)^{\alpha-1} .
\end{aligned}
$$

Plugging these two expressions into (A1), we end up with a fairly simple formula for $\theta$ in terms of $\varphi$ and $p$ :

$$
\theta=\frac{1}{1-(\varphi / p)^{1 / \alpha}}
$$

This shows that, for a given $p$, large- $\varphi$ countries are also large- $\theta$ countries, just as in our previous formulation. Furthermore, $\theta$ is a decreasing function of $p$, and hence the tightness of the financial constraint increases when trade liberalization increases the relative price $p$. Because the rental $\delta$ in (A2) is increasing in $p$ and decreasing in $\theta$, it follows that overall we must have that $\delta$ is increasing in $p$, which is our complementarity result ( $\delta / p$ is increasing in $p$ as well). We can similarly show that $w / \delta$ is decreasing in $p$, which confirms our anti-StolperSamuelson result.

Finally, it remains to show that the relative price $p$ increases in South when trade frictions are reduced. To prove this, it suffices to show that the autarky relative price $p$ is an increasing function of the primitive index $\varphi$ of financial development (so that $\varphi^{N}>\varphi^{S}$ implies $p^{N}>p^{S}$ ). Because $p$ is increasing in the endogenous tightness $\theta$, this is equivalent to showing that $\theta$ in (A3) is increasing 
in $\varphi$ when evaluated at the equilibrium autarky relative price $p=\{\mu \theta(1-$ $\eta) /[\eta(1-\mu \theta)]\}^{\alpha}$. This yields

$$
\theta=\frac{\mu(1-\eta)+\eta \varphi^{1 / \alpha}}{\mu(1-\eta)+\mu \eta \varphi^{1 / \alpha}}
$$

which is indeed increasing in $\varphi$. In sum, even when we account for the endogenous response of the credit constraint, in our benchmark model, trade integration allows South to trade at a higher relative price $p$, and this necessarily increases the real rental rate of capital.

\section{Appendix B}

\section{The Static Model with General Functional Forms}

In this appendix we provide further mathematical details on our "general model," which features general neoclassical production functions and general homothetic preferences. Letting $k=K / L$, we denote output per worker under each of the two production technologies by $f_{1}(k)$ and $f_{2}(k)$.

Let us first consider the equilibrium of the closed economy. As in the text, we assume that $\theta$ is low enough to ensure that the credit constraint binds and the amount of capital allocated to sector 1 is $K_{1}=\mu \theta K$. Letting $\psi_{1}$ denote the share of labor allocation to sector 1 , we can write the equilibrium conditions of this closed economy as

$$
\begin{aligned}
\psi_{1} f_{1}\left(\frac{\mu \theta}{\psi_{1}} \frac{K}{L}\right) & =\kappa(p)\left(1-\psi_{1}\right) f_{2}\left(\frac{1-\mu \theta}{1-\psi_{1}} \frac{K}{L}\right), \\
f_{1}^{\prime}\left(\frac{\mu \theta}{\psi_{1}} \frac{K}{L}\right) & =\delta+\lambda, \\
f_{1}\left(\frac{\mu \theta}{\psi_{1}} \frac{K}{L}\right)-f_{1}^{\prime}\left(\frac{\mu \theta}{\psi_{1}} \frac{K}{L}\right) \frac{\mu \theta}{\psi_{1}} \frac{K}{L} & =w, \\
p f_{2}^{\prime}\left(\frac{1-\mu \theta}{1-\psi_{1}} \frac{K}{L}\right) & =\delta, \\
p f_{2}\left(\frac{1-\mu \theta}{1-\psi_{1}} \frac{K}{L}\right)-p f_{2}^{\prime}\left(\frac{1-\mu \theta}{1-\psi_{1}} \frac{K}{L}\right) \frac{1-\mu \theta}{1-\psi_{1}} \frac{K}{L} & =w .
\end{aligned}
$$

The first condition ensures goods market equilibrium (remember that $\kappa(p)$ denotes the relative demand for good 1). The next two conditions characterize factor demand in sector 1 , and the last two characterize factor demand in sector 
2. After log-differentiating the above system (B1) and after a few manipulations we obtain

$$
\begin{aligned}
\hat{\psi}_{1}+\alpha_{1}\left(\hat{\theta}-\hat{\psi}_{1}+\hat{k}\right) & =-\frac{\psi_{1}}{1-\psi_{1}} \hat{\psi}_{1}+\varepsilon \hat{p}+\alpha_{2}\left(-\frac{\mu \theta}{1-\mu \theta} \hat{\theta}+\frac{\psi_{1}}{1-\psi_{1}} \hat{\psi}_{1}+\hat{k}\right), \\
-\frac{1-\alpha_{1}}{\sigma_{1}}\left(\hat{\theta}-\hat{\psi}_{1}+\hat{k}\right) & =\frac{\delta}{\delta+\lambda} \hat{\delta}+\frac{\lambda}{\delta+\lambda} \hat{\lambda}, \\
0 & =\left(1-\alpha_{1}\right) \hat{w}+\alpha_{1}\left(\frac{\delta}{\delta+\lambda} \hat{\delta}+\frac{\lambda}{\delta+\lambda} \hat{\lambda}\right), \\
\hat{\delta} & =\hat{p}-\frac{1-\alpha_{2}}{\sigma_{2}}\left(-\frac{\mu \theta}{1-\mu \theta} \hat{\theta}+\frac{\psi_{1}}{1-\psi_{1}} \hat{\psi}_{1}+\hat{k}\right), \\
\hat{p} & =\left(1-\alpha_{2}\right) \hat{w}+\alpha_{2} \hat{\delta},
\end{aligned}
$$

where hats denote percentage changes in the variables and the following definitions have been used:

$$
\begin{aligned}
\alpha_{i} & \equiv \frac{f_{i}^{\prime}\left(k_{i}\right) k_{i}}{f_{i}\left(k_{i}\right)}, \\
\sigma_{i} & \equiv \frac{\partial \ln k_{i}}{\partial \ln \left\{\left[f_{i}\left(k_{i}\right)-f_{i}^{\prime}\left(k_{i}\right) k_{i}\right] / f_{i}^{\prime}\left(k_{i}\right)\right\}}, \\
\varepsilon & \equiv \frac{\kappa^{\prime}(p) p}{\kappa(p)} .
\end{aligned}
$$

These correspond to sector $i$ 's elasticity of output with respect to capital (or one minus the labor share in sector $i$ ), sector $i$ 's elasticity of substitution between capital and labor, and the elasticity of substitution in consumption between goods 1 and 2.

The system (B2) can be solved to obtain $\hat{p}, \hat{w}, \hat{\delta}, \hat{\lambda}$, and $\hat{\psi}_{1}$ as a function of $\hat{\theta}$ and $\hat{k}$. These expressions shed light on the cross-country variation in prices and the allocation of labor under autarky. We are particularly interested in exploring whether the relative price $p$ is larger in North or South. After some fairly cumbersome algebra we obtain

$$
\begin{aligned}
\hat{p}= & \frac{\left\{\frac{1-\alpha_{1}+\left[\psi_{1} /\left(1-\psi_{1}\right)\right]\left(1-\alpha_{2}\right)}{1+\left(\sigma_{1} \alpha_{2} / \alpha_{1} \sigma_{2}\right)\left[\psi_{1} /\left(1-\psi_{1}\right)\right]}\right\}\left(1+\frac{\sigma_{1}}{\alpha_{1}} \frac{\alpha_{2}}{\sigma_{2}} \frac{\mu \theta}{1-\mu \theta}\right)+\left(\alpha_{1}+\alpha_{2} \frac{\mu \theta}{1-\mu \theta}\right)}{\varepsilon+\frac{\sigma_{1}}{\alpha_{1}} \frac{1-\alpha_{1}+\left[\psi_{1} /\left(1-\psi_{1}\right)\right]\left(1-\alpha_{2}\right)}{1+\left(\sigma_{1} \alpha_{2} / \alpha_{1} \sigma_{2}\right)\left[\psi_{1} /\left(1-\psi_{1}\right)\right]}} \hat{\theta} \\
& +\frac{\alpha_{1} \sigma_{2}\left(1-\alpha_{2}\right)-\left(1-\alpha_{1}\right) \sigma_{1} \alpha_{2}}{\left\{\varepsilon+\frac{\sigma_{1}}{\alpha_{1}} \frac{1-\alpha_{1}+\left[\psi_{1} /\left(1-\psi_{1}\right)\right]\left(1-\alpha_{2}\right)}{1+\left(\sigma_{1} \alpha_{2} / \alpha_{1} \sigma_{2}\right)\left[\psi_{1} /\left(1-\psi_{1}\right)\right]}\right\}\left[\alpha_{1} \sigma_{2}\left(1-\psi_{1}\right)+\psi_{1} \sigma_{1} \alpha_{2}\right]}
\end{aligned}
$$


which confirms our claim in proposition 6.

We can now move to an analysis of the small open economy. Our goal here is to show that, for general technologies and preferences, the real rental rate of capital is an increasing function of $p$. We again log-differentiate the above system, but this time ignoring the goods market condition and treating $p$ as parametric. This amounts to solving for $\hat{w}, \hat{\delta}, \hat{\lambda}$, and $\hat{\psi}_{1}$ as a function of $\hat{p}, \hat{\theta}$, and $\hat{k}$. We focus here on the value of $\hat{\delta}$ :

$$
\begin{aligned}
\hat{\delta}= & \frac{\psi_{1} \sigma_{1}+\alpha_{1} \sigma_{2}\left(1-\psi_{1}\right)}{\psi_{1} \sigma_{1} \alpha_{2}+\alpha_{1} \sigma_{2}\left(1-\psi_{1}\right)} \hat{p}-\frac{\left(\psi_{1}-\theta \mu\right) \alpha_{1}\left(1-\alpha_{2}\right)}{\left[\alpha_{1} \sigma_{2}\left(1-\psi_{1}\right)+\psi_{1} \sigma_{1} \alpha_{2}\right](1-\theta \mu)} \hat{\theta} \\
& -\frac{\alpha_{1}\left(1-\alpha_{2}\right)}{\alpha_{1} \sigma_{2}\left(1-\psi_{1}\right)+\psi_{1} \sigma_{1} \alpha_{2}} \hat{k} .
\end{aligned}
$$

Notice that the rental rate $\delta$ is necessarily increasing in $p$, and so is $\delta / p$, since the coefficient of $\hat{p}$ is strictly larger than one (for $\alpha_{2}<1$ ). Hence, as long as trade integration raises the relative price $p$ in South, it also raises the rental rate of capital in terms of both sectors' output.

This confirms the validity of proposition 5 as long as $p_{\text {aut }}^{N}>p_{\text {aut }}^{S}$ is a sufficient condition for $p$ increasing in South as a result of trade integration. In the small open economy case, this is obvious, but it remains true for the case in which both countries are large. In such a case, it will still necessarily be true that the world equilibrium price will fall somewhere between the two autarky relative prices, and thus trade integration corresponds to an increase in $p$ from the point of view of South whenever $p_{\text {aut }}^{N}>p_{\text {aut }}^{S}$. The key for this result is that relative demand of good 1 in each country is monotonically increasing in $p$ (because of homothetic preferences), whereas the relative supply of good 1 in each country is monotonically decreasing in $p$ (because $K_{1}$ is independent of $p$ whereas $L_{1}$ decreases in $p$ ). Hence, for any price outside the interval $\left(p_{\text {aut }}^{N}, p_{\text {aut }}^{S}\right)$, an excess relative demand in one country would not be compensated by an excess relative supply in the other country. This same argument explains why South will feature net exports of good 2 as long as $p_{\text {aut }}^{N}>p_{\text {aut }}^{S}$. This completes the proof of proposition 5.

As discussed in the text, the rise in $\delta$ (and $\delta / p$ ) induced by trade is the key feature that leads to complementarity between trade flows and capital flows in our model. Whether the increase in $\delta$ is large enough to lead to $\delta^{S}>\delta^{N}$ with free trade depends on whether relative factor endowment differences are large relative to factor intensity differences and differences in financial contractibility. To be more precise, the condition that ensures $\delta^{S}>\delta^{N}$ is given by

$$
\left(\frac{\psi_{1}}{1-\psi_{1}}-\frac{\mu \theta}{1-\mu \theta}\right) \hat{\theta}+\left(\frac{1}{1-\psi_{1}}\right) \hat{k}>0 .
$$

Or, more simply, all that we require is that North operates sector 2's technology at a higher capital-labor ratio than South does. As argued in the text, sufficiently large differences in capital-labor ratios between North and South will ensure that this condition is satisfied.

It is straightforward to show, however, that this condition also holds in the case of symmetric (neoclassical) production functions and no differences in 
$K / L$ across countries. In such a case, the analogue of equation (5) equating the value of the marginal product of labor across sectors is

$$
F_{L}\left(\frac{\mu \theta^{j} K}{\psi_{1}^{j} L}\right)=p F_{L}\left(\frac{\left(1-\mu \theta^{j}\right) K}{\left(1-\psi_{1}^{j}\right) L}\right) \text { for } j=N, S,
$$

where $F_{L}(\cdot)$ denotes the marginal product of labor and $F_{L}^{\prime}(\cdot)>0$. As shown above, for general homothetic preferences and symmetric production functions, it continues to be the case that $p<1$ as long as the financial constraint binds in North. From equation (B4), this immediately implies that $\psi_{1}^{j} /\left(1-\psi_{1}^{j}\right)>\mu \theta^{j} /\left(1-\mu \theta^{j}\right)$, and thus $\delta^{S}>\delta^{N}$. This confirms the validity of proposition 7 .

\section{Appendix C}

\section{External Dependence, Capital Intensity, and Factor Substitution}

In this appendix we provide more details on the correlations reported in Section IV. We follow Rajan and Zingales (1998) in measuring financial dependence as the fraction of total capital expenditures not financed by internal cash flow. This is computed at the three-digit SIC level and averaged over the period 198089 using Compustat data, as in Chor (2008). We correlate this measure with the labor share in that industry $\left(1-\alpha_{i}\right)$, which we compute using the NBER-CES Manufacturing Industry Database as the ratio of total payroll to total value added in a given three-digit industry, averaged over the period 1980-89. The correlation between the two measures is 0.034 . We next correlate financial dependence with an estimate of the elasticity of substitution between capital and labor in a given industry $\left(\sigma_{i}\right)$. This latter measure is computed as follows. The NBER-CES Manufacturing Industry Database provides data on total payroll, number of employees, real capital stock, and value added for each four-digit SIC industry. With these series we construct a proxy for the average wage-rental ratio (where wage $=$ payroll $/$ employees and rental $=[$ value added - payroll $] /$ real capital stock) and an average capital-labor ratio in a particular three-digit SIC industry. For each industry, we then run a regression of the capital-labor ratio on the wagerental ratio and a time trend (that controls for factor-biased technological progress) during the period 1958-96. The resulting estimates are our measures of substitutability, and their correlation with financial dependence is equal to 0.012. We have also experimented with running each three-digit industry regression with four-digit SIC-level data, including four-digit fixed effects that allow for Hicks-neutral shifts in technologies across subindustries within a three-digit industry. The results are very similar. Our final exercise is to use the above measures to compute an industry measure of $\alpha_{i} /\left[\left(1-\alpha_{i}\right) \sigma_{i}\right]$, as suggested by the model in Section IV. The correlation of this term with financial dependence continues to be very small $(-0.026)$.

\section{Appendix D}

\section{Details on the Dynamic Model}

In this appendix we provide further details on the determination of the steady 
state in our dynamic model in Section V. Our first goal is to reduce the dynamics of the model to two differential equations in two variables, namely, the capital stock $K_{t}^{j}$ and the share of wealth in the hands of entrepreneurs $\tilde{\mu}_{t^{*}}^{j}$

\section{Closed Economy Equilibrium}

For the autarky case, first plug equations (8), (9), (11), (15), and (23) into (24), with $\tilde{\mu}_{t}^{j}$ replacing $\mu$, to obtain the following law of motion equation for physical capital:

$$
\frac{d K_{t}^{j}}{d t}=Z\left(\frac{\tilde{\mu}_{t}^{j} \theta^{j}}{\eta}\right)^{\alpha \eta}\left(\frac{1-\tilde{\mu}_{t}^{j} \theta^{j}}{1-\eta}\right)^{\alpha(1-\eta)}\left(K_{t}^{j}\right)^{\alpha} L^{1-\alpha}-\phi K_{t}^{j}
$$

Working with equations (21) and (22) and plugging again (8), (9), (11), (15), and (23), we obtain the following law of motion for the share of wealth $\tilde{\mu}_{t}^{j}$ in the hands of entrepreneurs:

$$
\frac{d \tilde{\mu}_{t}^{j}}{d t}=\left[\alpha\left(1-\tilde{\mu}_{t}^{j}\right)\left(\frac{\eta-\tilde{\mu}_{t}^{j} \theta^{j}}{1-\tilde{\mu}_{t}^{j} \theta^{j}}\right)-\left(\tilde{\mu}_{t}^{j}-\mu\right)(1-\alpha)\right] Z\left(\frac{\tilde{\mu}_{t}^{j} \theta^{j}}{\eta}\right)^{\alpha \eta}\left(\frac{1-\tilde{\mu}_{t}^{j} \theta^{j}}{1-\eta}\right)^{\alpha(1-\eta)}\left(\frac{K_{t}^{j}}{L}\right)^{\alpha-1} .
$$

Log-linearizing the system of differential equations in (D1) and (D2) around the steady state $\left(K^{j}, \tilde{\mu}^{j}\right)$, we obtain

$$
\left[\begin{array}{c}
\frac{d \log \left(K_{t}^{j}\right)}{d t} \\
\frac{d \log \left(\tilde{\mu}_{t}^{j}\right)}{d t}
\end{array}\right]=\left[\begin{array}{cc}
-(1-\alpha) \phi & \frac{\eta-\tilde{\mu}^{j} \theta^{j}}{\tilde{\mu}^{j} \theta^{j}\left(1-\tilde{\mu}^{j} \theta^{j}\right)} \alpha \phi \\
0 & -\left[1+\frac{\left(\theta^{j}-1\right) \alpha(1-\eta)}{\left(1-\tilde{\mu}^{j} \theta^{j}\right)^{2}}\right] \phi
\end{array}\right]\left[\begin{array}{c}
\log \left(K_{t}^{j}\right)-\log \left(K^{j}\right) \\
\log \left(\tilde{\mu}_{t}^{j}\right)-\log \left(\tilde{\mu}^{j}\right)
\end{array}\right] .
$$

This immediately implies that the two eigenvalues associated with the dynamic system are both negative, and thus the system is stable. We can thus safely characterize the steady state of the system.

Next, setting $d K_{t}^{j} / d t=0$ in (D1), we obtain the steady-state physical capital stock in (26); setting the growth of $\tilde{\mu}_{t}^{j}$ in (D2) to zero, we obtain that the steadystate value of $\tilde{\mu}_{t}^{j}$ must satisfy

$$
\alpha\left(1-\tilde{\mu}_{\text {aut }}^{j}\right)\left(\frac{\eta-\tilde{\mu}_{\text {aut }}^{j} \theta^{j}}{1-\tilde{\mu}_{\text {aut }}^{j} \theta^{j}}\right)-\left(\tilde{\mu}_{\text {aut }}^{j}-\mu\right)(1-\alpha)=0 .
$$

We next verify that as long as assumption 1 holds (i.e., $\eta>\mu \theta$ ), this equation determines a unique solution for $\tilde{\mu}_{\text {aut }}^{j}$, and this solution satisfies $\mu \theta^{j}<\tilde{\mu}_{\text {aut }}^{j} \theta^{j}<\eta$. Uniqueness of the solution follows from the fact that the left-hand side of (D3) is monotonically decreasing in $\tilde{\mu}_{\text {aut }}^{j}$. The fact that $\tilde{\mu}_{\text {aut }}^{j} \theta^{j}<\eta$ can be established by contradiction. For any $\tilde{\mu}_{t}^{j}>\eta / \theta^{j}$, financial constraints would not bind and entrepreneurs would obtain no rents. Given the overlapping generations structure of the model, this would imply that in a steady-state equilibrium with $\tilde{\mu}_{\text {aut }}^{j} \theta^{j}>\eta$, we would necessarily have $\tilde{\mu}_{\text {aut }}^{j}=\mu$ (this can be formally proved by solving for the steady-state value of $\tilde{\mu}_{\text {aut }}^{j}$ whenever the Lagrange multiplier $\lambda_{t}^{j}$ is set to zero). But then $\mu \theta^{j}=\tilde{\mu}_{\text {aut }}^{j} \theta^{j}>\eta$ would contradict assumption 1 . Hence, we must have 
$\tilde{\mu}_{\text {aut }}^{j} \theta^{j}<\eta$. Inspection of equation (D3) then immediately reveals that $\tilde{\mu}_{\text {aut }}^{j}>\mu$. In words, the steady-state share of wealth in the hands of entrepreneurs exceeds their share in the population but is never high enough to let the economy "escape" from financial constraints.

For the main results in the text, it is also important to show that $\tilde{\mu}_{\mathrm{aut}}^{j} \theta^{j}$ is a monotonically increasing function of $\theta^{j}$. For that purpose, it is useful to define $\Lambda_{\text {aut }}^{j} \equiv \tilde{\mu}_{\text {aut }}^{j} \theta^{j}$ and rewrite equation (D3) as follows:

$$
\alpha\left(\theta^{j}-\Lambda_{\text {aut }}^{j}\right)\left(\frac{\eta-\Lambda_{\text {aut }}^{j}}{1-\Lambda_{\text {aut }}^{j}}\right)-\left(\Lambda_{\text {aut }}^{j}-\mu \theta^{j}\right)(1-\alpha)=0 .
$$

Straightforward differentiation indicates that the left-hand side is decreasing in $\Lambda_{\text {aut }}^{j}$ and increasing in $\theta^{j}$ (given that $\eta>\Lambda_{\text {aut }}^{j}$ ). Hence, by the implicit function theorem, we must have that $\Lambda_{\text {aut }}^{j} \equiv \tilde{\mu}_{\text {aut }}^{j} \theta^{j}$ is increasing in $\theta^{j}$.

\section{Free-Trade Equilibrium}

Working with equations (21), (22), (23), (24), and the expressions for factor prices in the open economy static model (with $\tilde{\mu}_{t}^{j}$ replacing $\mu$ ), we obtain the following laws of motion for physical capital and the share of wealth in the hands of entrepreneurs:

$$
\begin{aligned}
\frac{d K_{t}^{j}}{d t} & =\frac{\left[\left(1-\tilde{\mu}_{t}^{j} \theta^{j}\right) p^{1 / \alpha}+\tilde{\mu}_{t}^{j} \theta^{j}\right]^{\alpha}}{(p)^{1-\eta}} Z\left(K_{t}^{j}\right)^{\alpha} L^{1-\alpha}-\phi K_{t}^{j}, \\
\frac{d \tilde{\mu}_{t}^{j}}{d t} & =\frac{\frac{\alpha\left(1-\tilde{\mu}_{t}^{j}\right)\left(1-p^{1 / \alpha}\right) \tilde{\mu}_{t}^{j} \theta^{j}}{\left(1-\tilde{\mu}_{t}^{j} \theta^{j}\right) p^{1 / \alpha}+\tilde{\mu}_{t}^{j} \theta^{j}}-\left(\tilde{\mu}_{t}^{j}-\mu\right)(1-\alpha)}{(p)^{1-\eta}}\left\{\left[\left(1-\tilde{\mu}_{t}^{j} \theta\right) p^{1 / \alpha}+\tilde{\mu}_{t}^{j} \theta\right]\right\}^{\alpha} Z\left(\frac{K_{t}^{j}}{L}\right)^{\alpha-1},
\end{aligned}
$$

where $p$ is the relative price in North, which for simplicity is assumed to have reached its steady state.

Log-linearizing the system of differential equations in (D1) and (D2) around the steady state, it is straightforward to verify that the system is stable, just as it was in the closed economy case. Setting $d K_{t}^{j} / d t=0$, we then obtain the steadystate physical capital stock $K_{\text {open }}^{j}$ in (28); setting $d \tilde{\mu}_{t}^{j} / d t=0$, we obtain that the steady-state value of $\tilde{\mu}_{t}^{j}$ must satisfy

$$
\frac{\alpha\left(1-\tilde{\mu}_{\mathrm{open}}^{j}\right)\left(1-p^{1 / \alpha}\right)}{\left(1-\tilde{\mu}_{\mathrm{open}}^{j} \theta^{j}\right) p^{1 / \alpha}+\tilde{\mu}_{\mathrm{open}}^{j} \theta^{j}} \frac{\tilde{\mu}_{\mathrm{open}}^{j} \theta^{j}}{\left(\tilde{\mu}_{\mathrm{open}}^{j}-\mu\right)(1-\alpha)}=1 .
$$

It is clear from inspection of this expression that $\tilde{\mu}_{\text {open }}^{j}>\mu$, whereas financial constraints will continue to bind in the long run (i.e., $\tilde{\mu}_{\text {open }}^{j}<\eta / \theta^{j}$ ) for the same reasons as argued in the closed economy scenario. Simple differentiation of the left-hand side of this expression indicates that both terms are decreasing in $\tilde{\mu}_{\text {open }}^{j}$, whereas the first one is clearly decreasing in $p$. By the implicit function theorem, it then follows that $\tilde{\mu}_{\text {open }}^{j}$ is lower the larger $p$ is, or in other words, trade liberalization lowers the share of wealth in the hands of entrepreneurs.

Finally, for some of our results it is also important to study how the product 
$\Lambda_{\text {open }}^{j}=\tilde{\mu}_{\mathrm{open}}^{j} \theta^{j}$ is affected by $p$ and $\theta^{j}$. For this purpose we rewrite (D4) as follows:

$$
\frac{\alpha\left(\theta^{j}-\Lambda_{\text {open }}^{j}\right)\left(1-p^{1 / \alpha}\right)}{\left(1-\Lambda_{\text {open }}^{j}\right) p^{1 / \alpha}+\Lambda_{\text {open }}^{j}} \frac{\Lambda_{\text {open }}^{j}}{\left(\Lambda_{\text {open }}^{j}-\mu \theta^{j}\right)(1-\alpha)}=1 .
$$

It is clear from inspection of this expression that the left-hand side is decreasing in $\Lambda_{\mathrm{open}}^{j}$ and $p$ and increasing in $\theta^{j}$. Hence, by the implicit function theorem, $\Lambda_{\mathrm{open}}^{j}=\tilde{\mu}_{\mathrm{open}}^{j} \theta^{j}$ increases in $\theta^{j}$ and decreases in $p$, as argued in the text.

\section{References}

Aghion, Philippe, Abhijit Banerjee, and Thomas Piketty. 1999. "Dualism and Macroeconomic Volatility.” Q.J.E. 114 (4): 1359-97.

Amano, Akihiro. 1977. "Specific Factors, Comparative Advantage and International Investment." Economica 44 (174): 131-44.

Antràs, Pol, and Ricardo J. Caballero. 2007. "Trade and Capital Flows: A Financial Frictions Perspective.” Working Paper no. 13241, NBER, Cambridge, MA.

. 2009. "On the Role of Financial Frictions and the Savings Rate during Trade Liberalizations.” Working paper, Harvard Univ. and Massachusetts Inst. Tech.

Aoki, Kosuke, Gianluca Benigno, and Nobuhiro Kiyotaki. 2006. "Adjusting to Capital Account Liberalization." Unpublished manuscript, London School Econ.

Bardhan, Pranab, and Kenneth Kletzer. 1987. "Credit Markets and Patterns of International Trade." J. Development Econ. 27 (1-2): 57-70.

Beck, Thorsten. 2002. "Financial Development and International Trade: Is There a Link?” J. Internat. Econ. 57 (1): 107-31.

Becker, Bo, and David Greenberg. 2007. "Financial Development, Fixed Costs and International Trade." Working paper, Harvard Bus. School.

Blanchard, Olivier J. 1985. "Debt, Deficits, and Finite Horizons." J.P.E. 93 (2): 223-47.

Boyd, John H., and Bruce D. Smith. 1997. "Capital Market Imperfections, International Credit Markets and Nonconvergence." J. Econ. Theory 73 (2): 33564.

Brecher, Richard A., and Ronald Findlay. 1983. "Tariffs, Foreign Capital and National Welfare with Sector-Specific Factors.” J. Internat. Econ. 14 (3-4): 27788.

Caballero, Ricardo J., Emmanuel Farhi, and Pierre-Olivier Gourinchas. 2008. “An Equilibrium Model of 'Global Imbalances' and Low Interest Rates.” A.E.R. 98 (1): 358-93.

Chesnokova, Tatyana. 2007. "Immiserizing Deindustrialization: A Dynamic Trade Model with Credit Constraints.” J. Internat. Econ. 73 (2): 407-20.

Chor, Davin. 2008. "Unpacking Sources of Comparative Advantage: A Quantitative Approach." Manuscript, Singapore Management Univ.

Gertler, Mark, and Kenneth S. Rogoff. 1990. "North-South Lending and Endogenous Domestic Capital Market Inefficiencies.” J. Monetary Econ. 26 (2): 245-66.

Jones, Ronald W. 1971. "A Three-Factor Model in Theory, Trade, and History." In Trade, Balance of Payments, and Growth: Essays in Honor of Charles P. Kindleberger, edited by Jagdish N. Bhagwati et al. Amsterdam: North-Holland.

. 1989. "Co-movements in Relative Commodity Prices and International Capital Flows: A Simple Model.” Econ. Inquiry 27 (1): 131-41. 
Ju, Jiandong, and Shang-Jin Wei. 2006. "Endowment versus Finance: A Wooden Barrel Theory of International Trade.” Discussion Paper no. 5109, Centre Econ. Policy Res., London.

King, Robert G., and Ross Levine. 1993. "Finance and Growth: Schumpeter Might Be Right.” Q.J.E. 108 (3): 717-37.

Kraay, Aart, Norman Loayza, Luis Servén, and Jaume Ventura. 2005. "Country Portfolios." J. European Econ. Assoc. 3 (4): 914-45.

Lucas, Robert. 1990. "Why Doesn't Capital Flow from Rich to Poor Countries?" A.E.R. 80 (3): 92-96.

Manova, Kalina. 2008. "Credit Constraints, Heterogeneous Firms and International Trade." Unpublished manuscript, Harvard Univ.

Markusen, James R. 1983. "Factor Movements and Commodity Trade as Complements.” J. Internat. Econ. 14 (3-4): 341-56.

Martin, Philippe, and Hélène Rey. 2006. "Globalization and Emerging Markets: With or without Crash?” A.E.R. 96 (5): 1631-51.

Matsuyama, Kiminori. 2005. "Credit Market Imperfections and Patterns of International Trade and Capital Flows.” J. European Econ. Assoc. 3 (2-3): 714-23.

Mendoza, Enrique G., Vincenzo Quadrini, and José-Victor Rios-Rull. 2007. "Financial Integration, Financial Deepness and Global Imbalances." Working Paper no. 12909, NBER, Cambridge, MA.

Mundell, Robert A. 1957. "International Trade and Factor Mobility." A.E.R. 47 (3): 321-35.

Neary, J. Peter. 1995. "Factor Mobility and International Trade." Canadian J. Econ. 28 (special issue): S4-S23.

Rajan, Raghuram G., and Luigi Zingales. 1998. "Financial Dependence and Growth." A.E.R. 88 (3): 559-86.

Reinhart, Carmen M., and Kenneth S. Rogoff. 2004. "Serial Default and the 'Paradox' of Rich to Poor Capital Flows." A.E.R. Papers and Proc. 94 (2): 5258.

Samuelson, Paul A. 1971. "Ohlin Was Right.” Swedish J. Econ. 73:365-84.

Shleifer, Andrei, and Robert W. Vishny. 1997. "A Survey of Corporate Governance." J. Finance 52 (2): 737-83.

Shleifer, Andrei, and Daniel Wolfenzon. 2002. "Investor Protection and Equity Markets." J. Financial Econ. 66 (1): 3-27.

Tirole, Jean. 2006. The Theory of Corporate Finance. Princeton, NJ: Princeton Univ. Press.

Weil, Philippe. 1989. “Overlapping Families of Infinitely-Lived Agents.” J. Public Econ. 38 (2): 183-98.

Wynne, José. 2005. "Wealth as a Determinant of Comparative Advantage." A.E.R. 95 (1): 226-54. 